\title{
Hyperconnectivity is a Fundamental Response to Neurological Disruption
}

\author{
Frank G. Hillary, Cristina A. Roman, \\ Umesh Venkatesan, and Sarah M. Rajtmajer
}

Ricardo Bajo, and Nazareth D. Castellanos

\begin{abstract}
Objective: In the cognitive and clinical neurosciences, the past decade has been marked by dramatic growth in a literature examining brain "connectivity" using noninvasive methods. We offer a critical review of the blood oxygen level dependent functional MRI (BOLD fMRI) literature examining neural connectivity changes in neurological disorders with focus on brain injury and dementia. The goal is to demonstrate that there are identifiable shifts in local and large-scale network connectivity that can be predicted by the degree of pathology. We anticipate that the most common network response to neurological insult is hyperconnectivity but that this response depends upon demand and resource availability. Method: To examine this hypothesis, we initially reviewed the results from 1,426 studies examining functional brain connectivity in individuals diagnosed with multiple sclerosis, traumatic brain injury, mild cognitive impairment, and Alzheimer's disease. Based upon inclusionary criteria, 126 studies were included for detailed analysis. Results: Results from 126 studies examining local and whole brain connectivity demonstrated increased connectivity in traumatic brain injury and multiple sclerosis. This finding is juxtaposed with findings in mild cognitive impairment and Alzheimer's disease where there is a shift to diminished connectivity as degeneration progresses. Conclusion: This summary of the functional imaging literature using fMRI methods reveals that hyperconnectivity is a common response to neurological disruption and that it may be differentially observable across brain regions. We discuss the factors contributing to both hyper- and hypoconnectivity results after neurological disruption and the implications these findings have for network plasticity.
\end{abstract}

Keywords: brain injury, Multiple Sclerosis, Alzheimer's Disease, connectivity, default mode network

In the past decade there has been an important shift in human functional neuroimaging with greater emphasis on examining the relationship between brain regions in place of local mean signal change (i.e., amplitude or "activation"). With the recent focus on the human connectome (Biswal et al., 2010) and adaptations of mathematical modeling to functional neuroimaging work, a nascent literature now examines neural network connectivity, or the synchronous behavior between brain regions, across distinct situational demands (e.g., task, rest; see Fox et al., 2005; Raichle et al., 2001; Raichle \& Snyder, 2007). In this article we aggregate the results of functional imaging studies in distinct neurological disorders with the goal of testing the hypothesis that a common response to neurological disruption is "hyperconnectivity," or increased covariance between network nodes compared to healthy subjects, and that this effect is observable until neural resource depletion renders this response unsustainable. We provide a theoretical framework for conceptualizing connectivity and then examine the primary results of 126 studies in the clinical literature to examine this framework.

\section{Introduction: Disconnecting the Brain}

Geschwind's tour de force 1965 publication Disconnexion Syndromes in Animal and Man reintroduced functional disconnection syndromes to the neurosciences spurring decades of research aimed at understanding the interplay between primary and association centers of brain function (Geschwind, 1965a, 1965b). This work bridged classical and "neo" associationism and, although several of the primary tenets were significantly refined over time, (see Damasio \& Galaburda, 1985; Mesulam, 1985), disconnection syndromes have been a central area of research in the clinical neurosciences since that time. For example, Gazzaniga and colleagues focused great attention on the functional consequences associated with complete dissection of the cerebral hemispheres via neurosurgical intervention (Gazzaniga \& Smylie, 1984; Gazzaniga et al., 1979; Luck et al., 1989). These studies led to nuanced observations about hemispheric specialization, including possible competing roles between the hemispheres. What is interesting is that even given the specific goal to "disconnect" the hemispheres via neurosurgical intervention, demonstrating hemisphere-specific 
effects and that the two hemispheres were not communicating remained controversial (see Seymour et al., 1994).

This brief historical account reveals two important points relevant to this review. First, there is a natural tension in the neurosciences between localism and associationism which has direct influence on both method and theory. Most recently, this history has been at least partially recapitulated in the sweeping shift in the functional imaging literatures from signal amplitude (i.e., blobs) to signal covariance (i.e., connections). Second, true brain "disconnection" is likely to be rare in neurological disorders, even when it is an explicit goal. Integration of input between brain regions is essential to brain functioning because excitatory neuronal inputs operating in isolation perform no meaningful computation or information processing; there is growing evidence that only through synchronous oscillatory behavior can neural systems achieve information transfer and integration (see Buzsaki, 2004; Sporns, 2011a). We argue that, with notable exceptions where specific physical disconnection has direct and evident consequences for functional connectivity (e.g., basal forebrain disruption in anterior communication artery aneurysm), the most common response to neurological disruption is functional hyperconnectivity. To examine this hyperconnectivity hypothesis, we focus our review on examples from the clinical neurosciences where a normally developed neural system is affected by injury (e.g., traumatic brain injury), disease (e.g., multiple sclerosis), and/or degeneration (e.g., mild cognitive impairment, dementia).

\section{Functional Disruption as a Result of Structural Disconnection}

It should be made clear that there is little doubt that many neurological disorders result in structural disconnection of the brain's network constituents. Hallmark features of a number of neurological disorders include axonal damage and degeneration with loss of brain volume in both gray and white matter compartments. For example in traumatic axonal injury (or "diffuse axonal injury"), it is established that inertial/tensile forces place incredible strain on axons in cortical and subcortical white matter resulting in a secondary metabolic cascade and degradation of axonal fibers over the course of the first few weeks following injury (Greer, McGinn, \& Povlishock, 2011). Similar effects are observed in multiple sclerosis where the disease processes result in axonal destruction characterized by Wallerian degeneration, which is well documented in animal models and post mordem studies (see Casanova et al., 2003). The global neural atrophy apparent in Alzheimer's is also well established as is the early targeted loss of tissue in mesial temporal and parietal regions leave little doubt that the disease results in loss of brain volume (see Alves et al., 2013 for recent review). Because a universal feature in neuropathology is tissue loss, "disconnection" is standard parlance to describe the consequences of brain injury and disease in the clinical neurosciences.

However, in the absence of a one-to-one relationship between structure and function in the brain, the consequences of structural brain changes for functional connectivity are much less clear. Functional connectivity can exist in the absence of direct structural connectivity (Sporns, 2011a). Borrowing from the cognitive aging literature, age-related tissue loss may disrupt one or more network connections, potentially even the most influential link(s) without complete disconnection from a broader network (Rypma et al., 2006). This conceptualization is consistent with the most common cognitive consequences in aging and neurological disorders; the result is often not an inability to process stimuli, but rather slowed and inefficient information processing of stimuli (see Demaree et al., 1999; Salthouse et al., 1991; Rypma et al., 2006; Salthouse et al., 1993). We propose here that the term "disconnection" as a heuristic for describing network changes after neurological disorders may misrepresent the influence of brain lesions on complex neural systems both acutely and after recovery. In the current article "disruption" is used to describe the physical changes in the brain resulting from neurological compromise and we use this term here in place of "disconnection" in order to (a) dissociate the functional response from the structural damage and (b) avoid any assumptions about the connectivity response to neurological insult

\section{A Model for Hyperconnectivity}

In the first decade using AMRI to examine the consequences of brain injury and disease, one common finding was that brain injury and disease resulted in increased neural resource use (for review see Hillary, 2008; Hillary et al., 2006). Similarly, the aging literature demonstrated reduced laterality in hemisphere-specific findings indicating more equally distributed representation of memory with age (see Dolcos et al., 2002 for review). These findings were based upon task-elicited signal change and generally did not focus on synchrony in the signal generated between regions of interest (ROI). We anticipate that task-based studies of signal amplitude hold implications for current work focused on network responses and that a common response to disruption/challenge is an increase in either number or strength of network connections.

For the purposes of this review, we conceptualize the hyperconnectivity observed in neurological disruption as a nonlinear process representing an interaction between (a) situational/transient demands, (b) the degree of challenge posed by neurological disruption, and (c) resource availability. With respect to situational demand, note that external stimulation need not be present-the natural variation in neural oscillatory behavior over time is an important determinant of connectivity readiness irrespective of overt stimulation (see Arieli, Sterkin, Grinvald, \& Aertsen, 1996; Buzsaki, 2004). Jointly, Figures $1 \mathrm{a}$ and $1 \mathrm{~b}$ represent the hypothesized neural network response to competing demands (i.e., variable resource demand vs. resource loss). When neural resource loss reaches some upper threshold, increased connectivity is no longer a viable response to situational demand (see Sheline \& Raichle, 2013; Tijms et al., 2013 for reviews). This relationship may not be a simple one, however, because although there is ample evidence that resource availability plays a critical role in network response where there is significant brain atrophy (e.g., in Alzheimer's disease $[\mathrm{AD}]$ ), not all network damage is catastrophic with disruption of highly critical nodes (or "hubs") being more deleterious to function in complex networks (Albert et al., 2000; Jeong, Tombor, Albert, Oltvai, \& Barabasi, 2000; Stam et al., 2009). Although connection strengths change during recovery, there is a ceiling for the maximum number of connections a neural system can take advantage of - connections cannot be limitless. To represent these factors schematically, the asymptote for maximal connectivity in Figure 1a is equivalent in both healthy and clinical populations with neurological insult resulting in an earlier rise in resource recruitment given situational demand. Thus the "critical injury threshold" in 


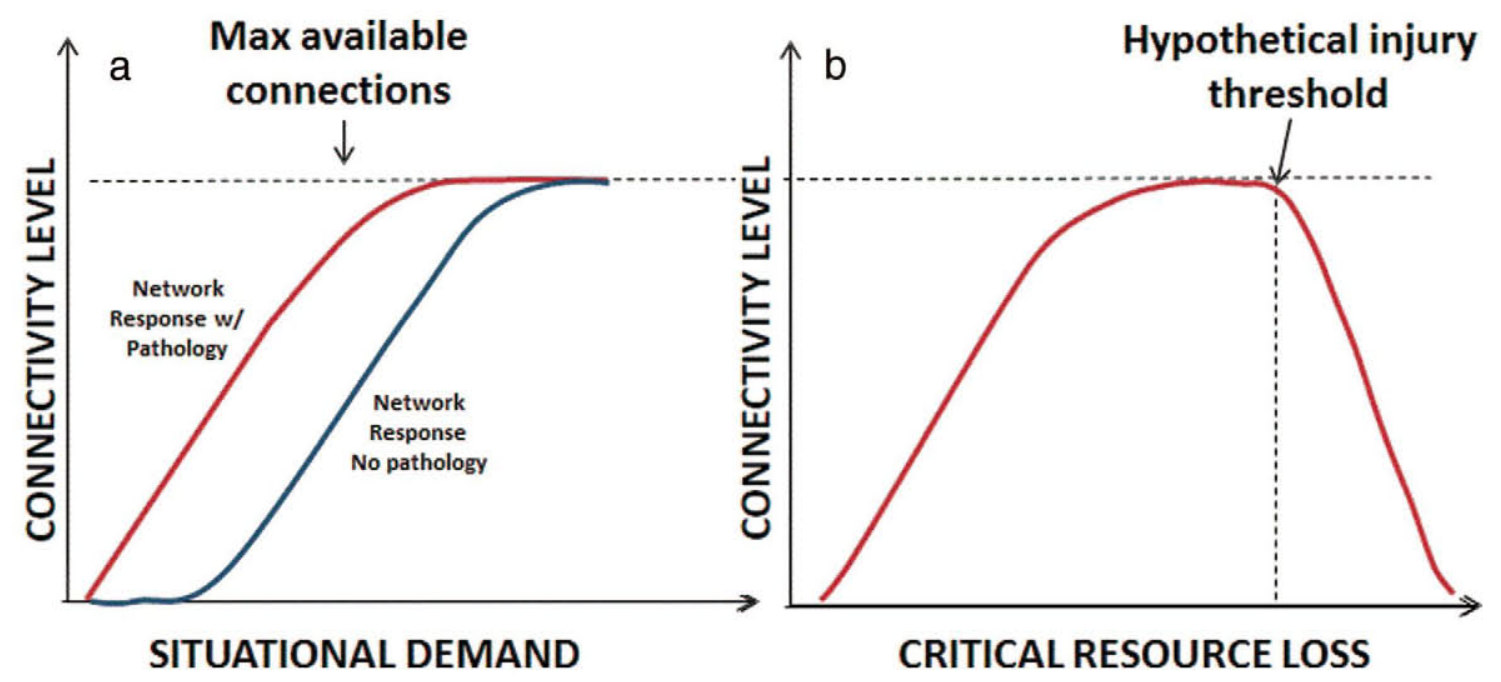

Figure 1. Schematic representation of proposed connectivity effects in neurological disorder. The color version of this figure appears in the online article only.

Figure $1 \mathrm{~b}$ will be determined by some combination of individual differences in cognitive reserve (or buffer against the onset of neurological insult, see Steffener et al., 2012; Stern, 2012) and the location of network disruption.

We assume that connectivity is transient and dependent upon momentary brain states including the network readiness in the absence of stimulation as well as during periods of perturbation (i.e., task). For example, the transient incorporation of available resources in a functional neural network has been demonstrated to be variable even within a scanning session (Bassett et al., 2011; Hillary et al., 2011a; Leonardi et al., 2013). We anticipate that these competing factors (transient demand vs. resource availability) have important implications for what we observe after neurological disruption as the population moves from adequate to inadequate resources over the life span (moving from left to right along the curve in Figure 1b).

To examine the schematic representation in Figures $1 \mathrm{a}$ and $1 \mathrm{~b}$ we conducted a literature review of brain connectivity in neurological disorders. In doing so, the following hypotheses were tested:

Hypothesis 1: A common consequence to neurological disruption is hyperconnectivity. This effect should be evident in cases of brain injury and disease where adequate neural resources are available for recruitment of connections.

Hypothesis 2: Consistent with a well-established literature (see Sheline \& Raichle, 2013), we anticipate that studies of $\mathrm{AD}$ will demonstrate connectivity loss in posterior regions including posterior cingulate cortex (PCC) and hippocampus.

Hypotheses 3: Given that MCI is a precursor to $\mathrm{AD}$, we anticipate that brain networks in $\mathrm{MCI}$ will be in a transition stage, demonstrating both residual hyperconnectivity occurring at the outset of neural resource disruption and hypoconnectivity consistent with suprathreshold resource loss in regions targeted by the pathophysiology of $\mathrm{AD}$.

\section{Brain Connectivity in Neurological Disorders: Literature Review}

In order to examine the hypotheses and the connectivity relationships proposed in Figures 1a, and 1b, we conducted a review within BOLD fMRI literature to capture effects along both the "situational demand" (Figure 1a) and "structural damage" (Figure 1b) functions. We reviewed articles using the PubMed search engine focusing on connectivity modeling in four clinical samples: moderate and severe traumatic brain injury (TBI), multiple sclerosis (MS), mild cognitive impairment (MCI), and dementia of the Alzheimer's type (AD). We anticipated that for Figure 1b, the first two groups (TBI and MS) would show greater hyperconnectivity than hypoconnectivity. We also anticipated that MCI would be at or near the "critical injury threshold" for structural damage so that both hyper- and hypoconnectivity would be evident, and that $\mathrm{AD}$ would show the greatest hypoconnectivity and little hyperconnectivity (consistent with the decline in connectivity beyond the critical injury threshold). The goal was to provide an inclusive summary of these functional imaging literatures so we accepted the varied definitions of "connections" offered in the studies included here, and incorporate distinct statistical measures of time series covariance including, for example (a) seed-based correlation of time series data, (b) psychophysiological interaction analysis, (c) independent component analysis, and (d) graph theory (see Supplementary tables).

\section{Literature Search}

The search strategy used the PubMed Database focusing on studies reporting functional imaging results examining brain "connectivity." To conduct the search, the following search terms were used: (a) traumatic brain injury + connectivity, (b) traumatic brain injury + network, (c) multiple sclerosis + connectivity, (d) multiple sclerosis + network, (e) mild cognitive impairment + connectivity, (f) mild cognitive impairment + network, (g) Alzheimer's + connectivity, and (h) Alzheimer's + network. Articles were included if they were available on PubMed prior to December 31, 2013, and were original 
research printed in English. After removing duplicates between searches, these eight search combinations produced a total of 1,426 peer reviewed articles (300 TBI, $182 \mathrm{MS}, 708 \mathrm{AD}$, and $236 \mathrm{MCI}$ ). From these 1,426 studies, we reviewed abstracts in order to apply second level exclusionary criteria, such as (a) structural imaging only, (b) no connectivituctural imaging onlyy analysis as a primary analysis in the study, (c) review article, (d) other pathology (e.g., epilepsy, schizophrenia), and (e) other reason (e.g., cases studies; methods studies; animal work). For example the search terms "traumatic brain injury + connectivity" revealed 273 articles where 14 were included $(5 \%)$ in the review and the remaining were excluded based upon the following criteria: (a) review articles $(n=74,27 \%)$; (b) other pathology (e.g., spinal cord injury, vegetative TBI, $n=63,23 \%$ ); (c) animal models or molecular/cellular work $(n=48,17 \%)$; (d) mild TBI $(n=$ $20,7 \%)$; (e) methods articles or data simulations ( $n=17,6 \%$ ); (f) structural imaging alone $(n=10,3 \%)$; (g) no connectivity measured ( $n=8,3 \%$ ); (h) EEG/ERP studies, signal amplitude only $(n=6$, $2 \%$ ); (i) case studies or serial case studies $(n=3,1 \%)$; (j) no imaging $(n=3,1 \%) ;(\mathrm{k})$ no comparison to health adults $(n=3)$; and $(1)$ language other than English $(n=1 ;<1 \%)$. Of note, the study of mild TBI using functional connectivity methods is a rapidly growing literature, but integration of these studies poses challenges because of the difficulty in diagnostics in mild injuries, the mixed etiologies in the literature (e.g., sports-related concussion, blast-related injury) and comorbidities within samples with regard personality/psychiatric factors (see Hou et al., 2012). Therefore, in order to guarantee that all studies included cases of verifiable neurological disruption, we included studies self-defined as the study of "moderate and severe" TBI. In the case of "methods articles," articles were excluded if betweengroups comparisons were not made and/or the primary goal was to examine algorithmic success in patient grouping based upon pattern classification or logistic regression (e.g., Wee et al., 2012). Articles were also excluded when the primary goal was to examine the influence of an intervention or drug and no initial group comparison was made affording the opportunity to examine relative group connectivity (e.g., Solé-Padullés et al., 2013). Finally, articles were excluded if no baseline comparison of connectivity was made between the clinical sample and healthy control sample (e.g., Bonnelle et al., 2012; Bonnelle et al., 2011) or the comparison was made but only based upon a specific contrast or manipulation (e.g., Palacios et al., 2012). Study inclusion was determined by thorough review of the study design and methods.

\section{Analytic strategy}

For the 126 studies meeting the inclusionary criteria, the methods and results were reviewed and the study findings are summarized as either increased connectivity compared with a healthy control sample $(+)$ or decreased connectivity compared to a healthy control sample $(-)$, or both increased and decreased connectivity compared with a healthy control sample $(+/-)$. We also summarize the methods used for examining brain connectivity within these literatures including (a) signal filtering, (b) movement correction, and (c) integration of behavioral data. Finally, in order to make direct comparisons between the four clinical literatures, we selected all "rest-only" studies for the four clinical samples and coded all significant findings in binary fashion for "hyper" and "hypo." Based upon these data, we examined the distribution of these findings and conducted a spatial mapping of the specific neuroanatomical findings (see below for procedure).

\section{Results of Literature Review}

\section{Study characteristics}

In the 126 studies reviewed here, $34 \%$ were studies of MCI, 30\% were studies of $\mathrm{AD}, 24 \%$ were studies of MS (or early MS), and $10 \%$ were studies of TBI. In addition, it was a goal to monitor the data preprocessing in these literatures with respect to three variables: (a) signal filtering, (b) movement correction, and (c) integration of behavior. A summary of the approaches used in this literature are summarized in Table 1. Supplementary Tables 2-4 provide summaries of the 126 studies included in this review.

\section{Testing Hypotheses: Frequency Results}

The Tables are organized based upon the clinical sample and the type of analysis conducted with focus on (a) "whole brain" analyses examining distributed networks or (b) analyses of networks linked with a specific region of interest (ROI; e.g., PCC in the default mode network, DMN). Figure 2 summarizes the findings from Tables after eliminating sample redundancies. MCI and AD findings are summarized separately in cases where both samples were included in the same study; 11 studies contribute to both the MCI and AD findings for Tables and Figure 2.

There are some consistencies in this literature predicted by the general framework offered in Figures $1 \mathrm{a}$ and $1 \mathrm{~b}$ and the associated hypotheses. First, consistent with Hypothesis 1, hyperconnectivity was a common response in TBI and MS where extensive neural atrophy is presumably not present. Second, in support of Hypothesis 2 , studies of $\mathrm{AD}$ were the least likely to demonstrate hyperconnectivity. Finally, consistent with Hypothesis 3, hypoconnectivity was very common in MCI but these samples were also more likely to exhibit hyperconnectivity compared with $\mathrm{AD}$ samples (62\% vs. $40 \%$ ).

\section{Spatial Mapping of Frequency Findings}

In order to examine the specific sites of hypo- and hyper- connectivity, findings from studies focused on rest-only were summarized in binary fashion ( -1 for less connectivity in clinical sample and +1 for greater connectivity in the clinical sample). For each group these values were input into a binary table sized $N \times M$, where $M$ is the number of reviewed studies and $N$ are the 102 ROIs established according to the AAL atlas (Tzourio-Mazoyer et al., 2002). The elements of that table can be 1 or -1 , coding for hyper- and hypoconnectivity findings, respectively. The results of studies were averaged over each ROI, 102-length array of both positive and negative values representing the net finding for each ROI. Before plotting these data, we separated the array into positive (hyperconnectivity) and negative (hypoconnectivity) values which were then input into MRIcroGL (http://www.mccauslandcenter.sc.edu/mricrogl/) for coordinate mapping and visualization of imaging findings. Figures $3 a-d$ are the summary plots for the four clinical groups revealing hyperconnectivity in TBI and MS samples and a stepwise decline in connectivity from $\mathrm{MCI}$ to $\mathrm{AD}$ studies.

\section{Distribution of Findings}

The spatial gradient of connectivity (e.g., relative anterior to posterior) was examined by viewing distributions of the binary connec- 
Table 1

Methodological Characteristics for Studies Included

\begin{tabular}{|c|c|c|c|c|c|}
\hline Sample & $\begin{array}{l}\text { MRI field } \\
\text { strength }\end{array}$ & $\begin{array}{c}\text { Filtering/nuisance } \\
\text { signal }\end{array}$ & $\begin{array}{l}\text { Movement } \\
\text { correction }\end{array}$ & $\begin{array}{c}\text { Behav } \\
\text { analysis }\end{array}$ & $\begin{array}{c}\text { Vol } \\
\text { (range/mean) }\end{array}$ \\
\hline \multirow{6}{*}{ TBI 14 studies } & & Temporal: $50 \%$ & Realign: $92 \%$ & & \\
\hline & $3 \mathrm{~T}: 100 \%$ & ICA: $21 \%$ & Regression: 7\% & Yes: $78 \%$ & Mean: 195.1 \\
\hline & & GSR: $14 \%$ & Group Comparison: $21 \%$ & No: $22 \%$ & Range: $128-300$ \\
\hline & & WM/CSF: $28 \%$ & Vol/slice corr: $7 \%$ & & \\
\hline & & Other: $35 \%$ & Other: $7 \%$ & & \\
\hline & & None/unk: $14 \%$ & & & \\
\hline \multirow[t]{6}{*}{ MS 31 studies } & & Temporal: $57 \%$ & Realign: $93 \%$ & & \\
\hline & 3T: $80 \%$ & ICA: $21 \%$ & Regression: $50 \%$ & Yes: $71 \%$ & Mean: 261.7 \\
\hline & $1.5 \mathrm{~T}: 20 \%$ & GSR: $3 \%$ & Group Comparison: $17 \%$ & No: $29 \%$ & Range: $60-600$ \\
\hline & & WM/CSF: $25 \%$ & Vol/slice corr: $17 \%$ & & \\
\hline & & None/unk: $35 \%$ & Unk: $7 \%$ & & \\
\hline & & Other: $21 \%$ & & & \\
\hline \multirow[t]{6}{*}{ MCI 44 studies } & & Temporal: $70 \%$ & Realign: $87 \%$ & & \\
\hline & 3T: $55 \%$ & ICA: $38 \%$ & Regression: $36 \%$ & Yes: $56 \%$ & Mean: 199.1 \\
\hline & $1.5 \mathrm{~T}: 40 \%$ & GSR: $21 \%$ & Group Comparison: $15 \%$ & No: $43 \%$ & Range: $80-360$ \\
\hline & unk: $4 \%$ & WM/CSF: $15 \%$ & Vol/slice/despike: $6 \%$ & & \\
\hline & & Other: $2 \%$ & Other: $11 \%$ & & \\
\hline & & None/unk: $17 \%$ & Unk: $4 \%$ & & \\
\hline \multirow[t]{6}{*}{ AD 46 studies } & & Temporal: $76 \%$ & Realign: $88 \%$ & & \\
\hline & 3T: $60 \%$ & ICA: $43 \%$ & Regression: $26 \%$ & Yes: $42 \%$ & Mean: 191.6 \\
\hline & $1.5 \mathrm{~T}: 35 \%$ & GSR: $10 \%$ & Group Comparison: $16 \%$ & No: $58 \%$ & Range: $100-360$ \\
\hline & Unk: $5 \%$ & WM/CSF: $17 \%$ & Vol/slice/despike: $4 \%$ & & \\
\hline & & Other: $5 \%$ & Other: $12 \%$ & & \\
\hline & & None/unk: $19 \%$ & Unk: $7 \%$ & & \\
\hline
\end{tabular}

Note. $\quad$ Behav $=$ behavioral; $\mathrm{TBI}=$ traumatic brain injury; $\mathrm{GSR}=$ global signal regression; $\mathrm{ICA}=$ independent component analysis; $\mathrm{T}=\mathrm{Tesla}$; unk = unknown; vol = volumes; $\mathrm{WM} / \mathrm{CSF}=$ white matter cerebral spinal fluid; $\mathrm{MS}=$ multiple sclerosis; $\mathrm{MCI}=$ mild cognitive impairment; $\mathrm{AD}=$ Alzheimer's disease. Method: Filtering/Nuisance signal: Temporal = use of a temporal filter (most commonly .08 Hz- $10 \mathrm{~Hz}$ ); WM/CSF: use signal from white matter and/or cerebrospinal fluid as regressor; Movement Correction: Realign: linear rigid-body coregistration, most commonly 6-parameter realignment of time series; Group Comparison: movement parameters directly compared between groups, Vol/slice corr: correction of movement effects on a slice-by-slice basis or volume-by-volume basis (i.e., frame-by-frame). Behav. Analysis: the frequency of examining connectivity results in the context of behavioral data.

tions across all significant findings in the 126 "rest-only" studies. Given the few studies in TBI and MS and the relative consistency in the findings in these subgroups, the data here were collapsed to form three separate distributions showing the connectivity findings along

\section{Connectivity Frequencies for all Studies}

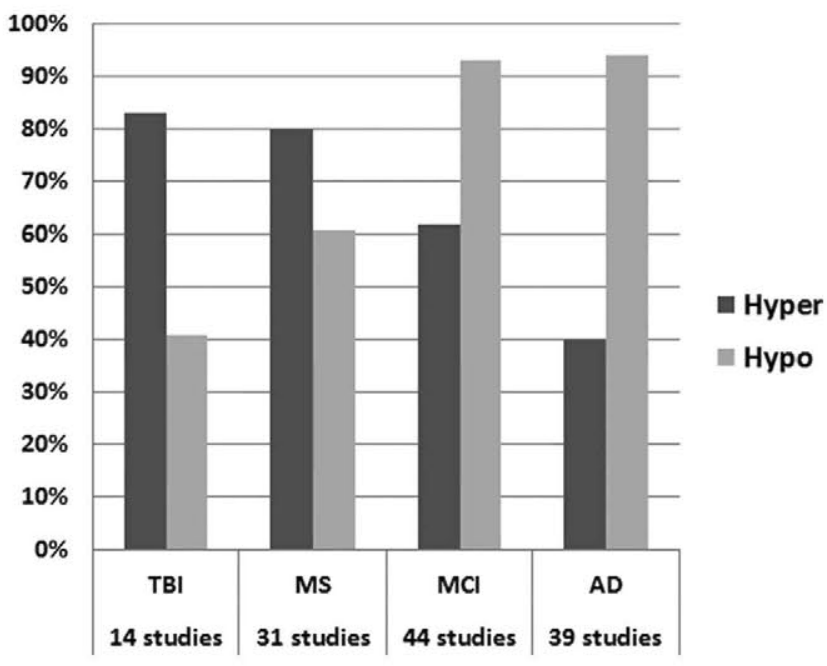

Figure 2. Connectivity findings for all studies. an anterior to posterior gradient. Frequencies (percentages) in this distribution are normalized by the total number of positive findings within each sample (hypo and hyper). These distributions reveal that TBI and MS show greater overall hyperconnectivity with the greatest increases occurring in (a) frontal, (b) DMN, and (c) posterior association areas (Figure 4a). MCI reveals a mixed distribution of both heightened hypo- and hyperactivation in anterior and posterior systems, but notable drop-out in DMN including PCC and hippocampus (Figure 4b). Finally, in $\mathrm{AD}$, the anterior to posterior gradient is most striking, where there is some evidence of residual hyperconnectivity in anterior regions, but largely hypoconnectivity across the brain and it becomes significantly more dramatic moving from anterior to posterior (Figure 4c)

\section{Discussion}

\section{Primary Findings}

Hyperconnectivity appears to be a common response to neurological injury and disease at both local and global levels consistent with the framework described here. Figures $3 a-d$ provide evidence for a transition from largely hyperconnectivity in brain injury and disease to a mixture of connectivity loss and gain in MCI and then to the significant network loss observed in $\mathrm{AD}$. The TBI samples demonstrate diminished medial frontal and anterior ACC connection loss possibly due to white matter disruption anteriorly coupled with re- 


\section{a: Traumatic Brain Injury Studies: 4, Subjects: 90}

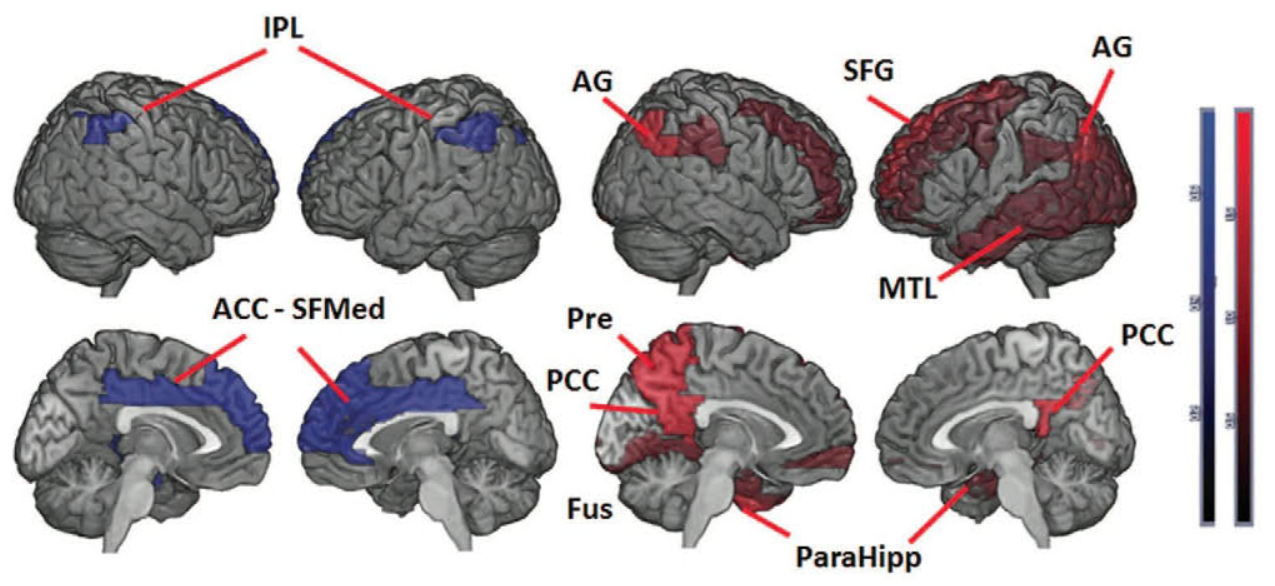

\section{Hypo-connectivity}

Hyper-connectivity

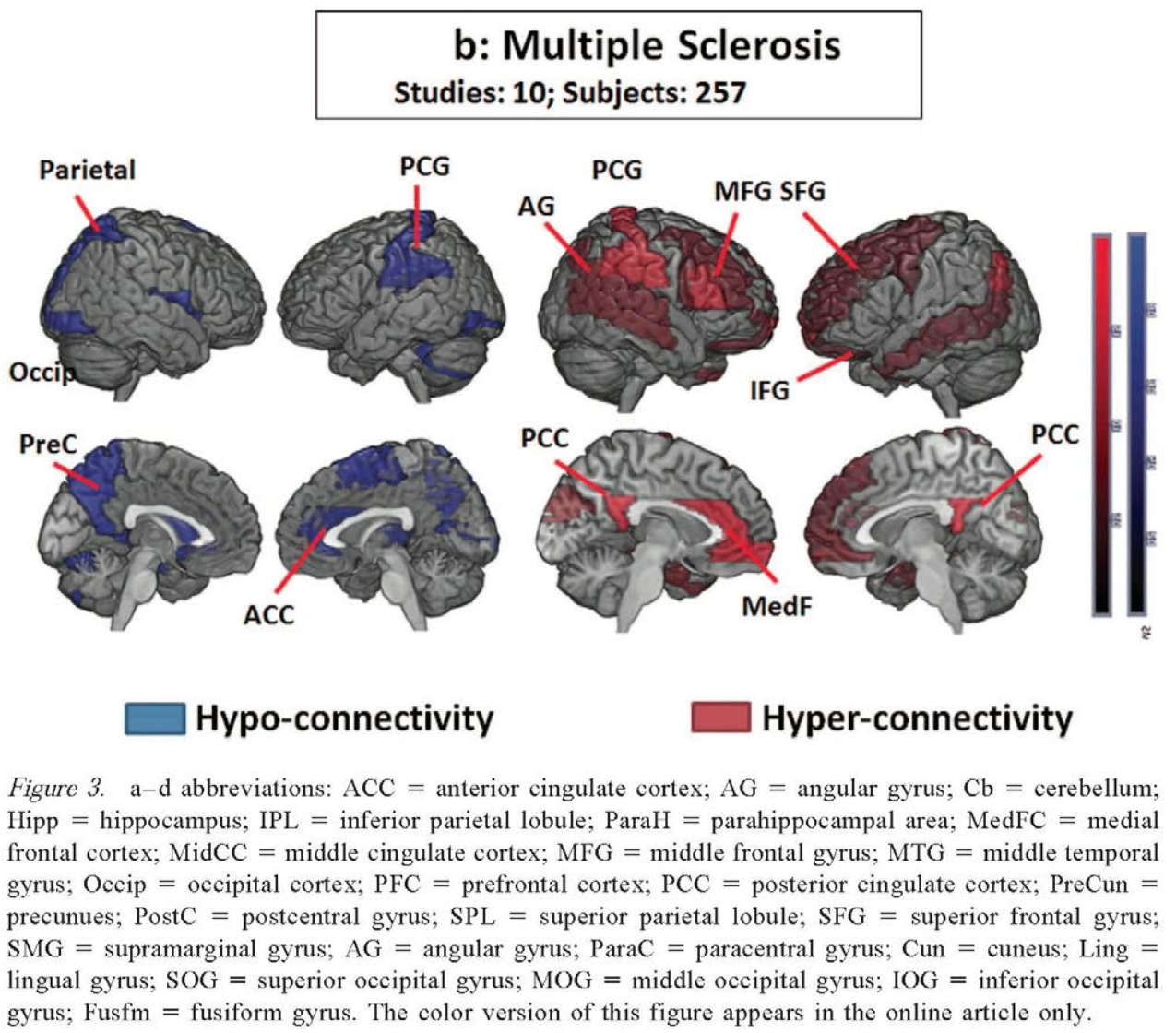

cruitment of parietal, posterior cingulated, and later frontal regions. In MS, there is similar recruitment of connections to that observed in TBI, which is also potentially due to subcortical white matter disruption. The MS studies also show a pattern of hypoconnectivity in visual and sensory-motor regions (see Figure $3 b$ ), which may be related to the visual and motor disturbances observed in MS. Finally, we see stepwise decline in connectivity from MCI to AD (Figures $3 \mathrm{c}-\mathrm{d}$; $4 \mathrm{~b}-\mathrm{c}$ ) whereby MCI shows global signs of connection loss coupled with a hyperconnectivity occurring in frontal, posterior association areas, and cerebellum. This posterior recruitment of connections is essentially absent in $\mathrm{AD}$, where the only residual signs of hyperconnectivity remain in frontal systems. 


\section{c: Mild Cognitive Impairment Studies: 28; Subjects: 579}

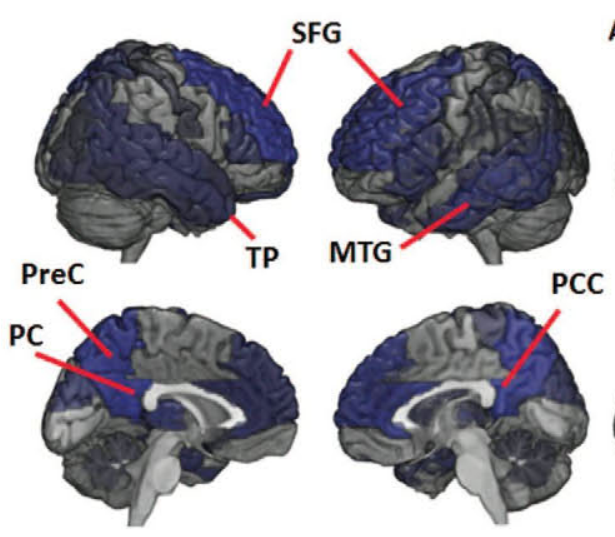

Hypo-connectivity

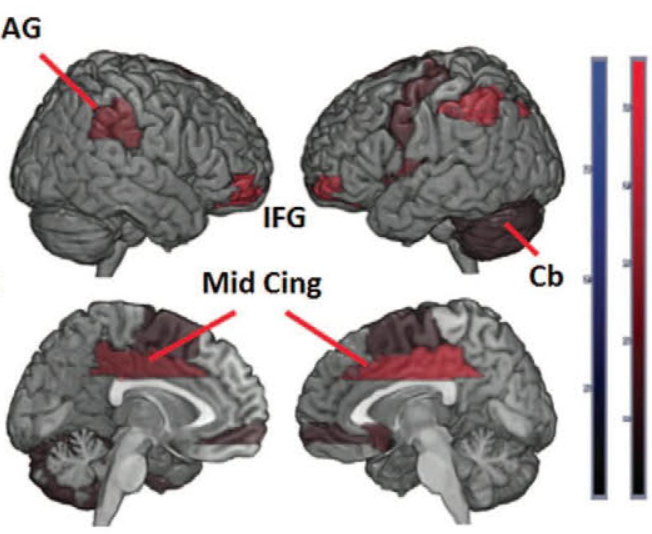

Hyper-connectivity

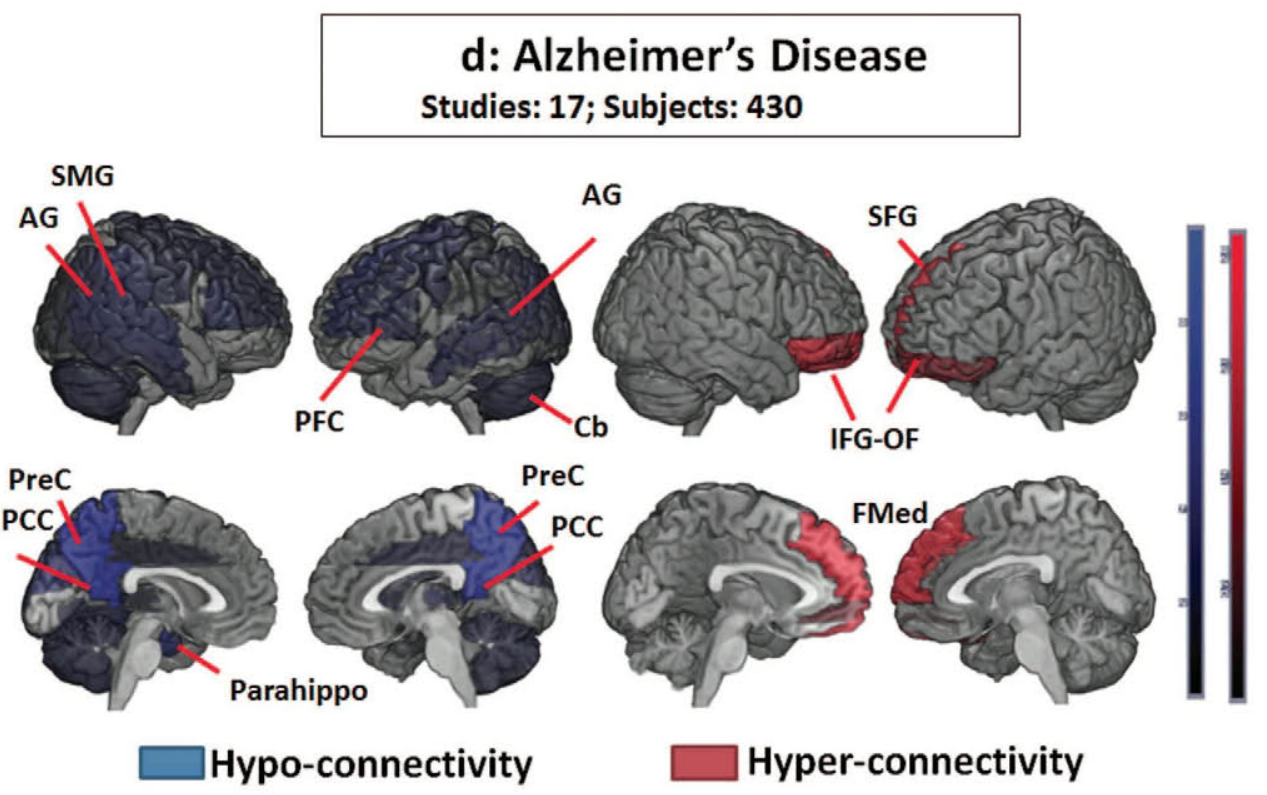

Figure 3 (continued)

The Nature of Hyperconnectivity in Brain Imaging Studies

To provide context for understanding the meaning of the current findings, additional consideration should be given to how connections are determined in connectivity modeling. The goal in connectivity analyses is to determine how signals from spatially distinct brain regions covary, but in examining hypo- and hyperconnectivity, it is also important to consider possible mechanisms for change in signal covariance related to underlying brain activity. Recently it has been demonstrated that local signal properties may be playing a widespread and unintended role in observed correlations between ROIs in the brain (see Bassett et al., 2011; Hillebrand et al., 2012; Zalesky et al., 2012). In particular, there is evidence of a positive relationship between source power (i.e., amplitude) and signal covariance in healthy adults (Hillebrand et al., 2012) and clinical samples (Medaglia et al., in press). One explanation for this could be that reliable estimates of functional connectivity require sufficient signal-to-noise ratio (SNR), introducing a methodological bias such that connectivity between regions with lower source power may be missed or underestimated using classic correlation thresholding schemes. However, there is also evidence that the increased likelihood of observing connectivity in high SNR is not solely attributable to statistical sensitivity. Investigators have observed a direct relationship between spiking output during neural firing and phase locking across nodes, thus resulting in higher measured connectivity/coherence (Chawla et al., 1999, 2000). These latest findings offer evidence that the increased connectivity observed in the literature summarized here 

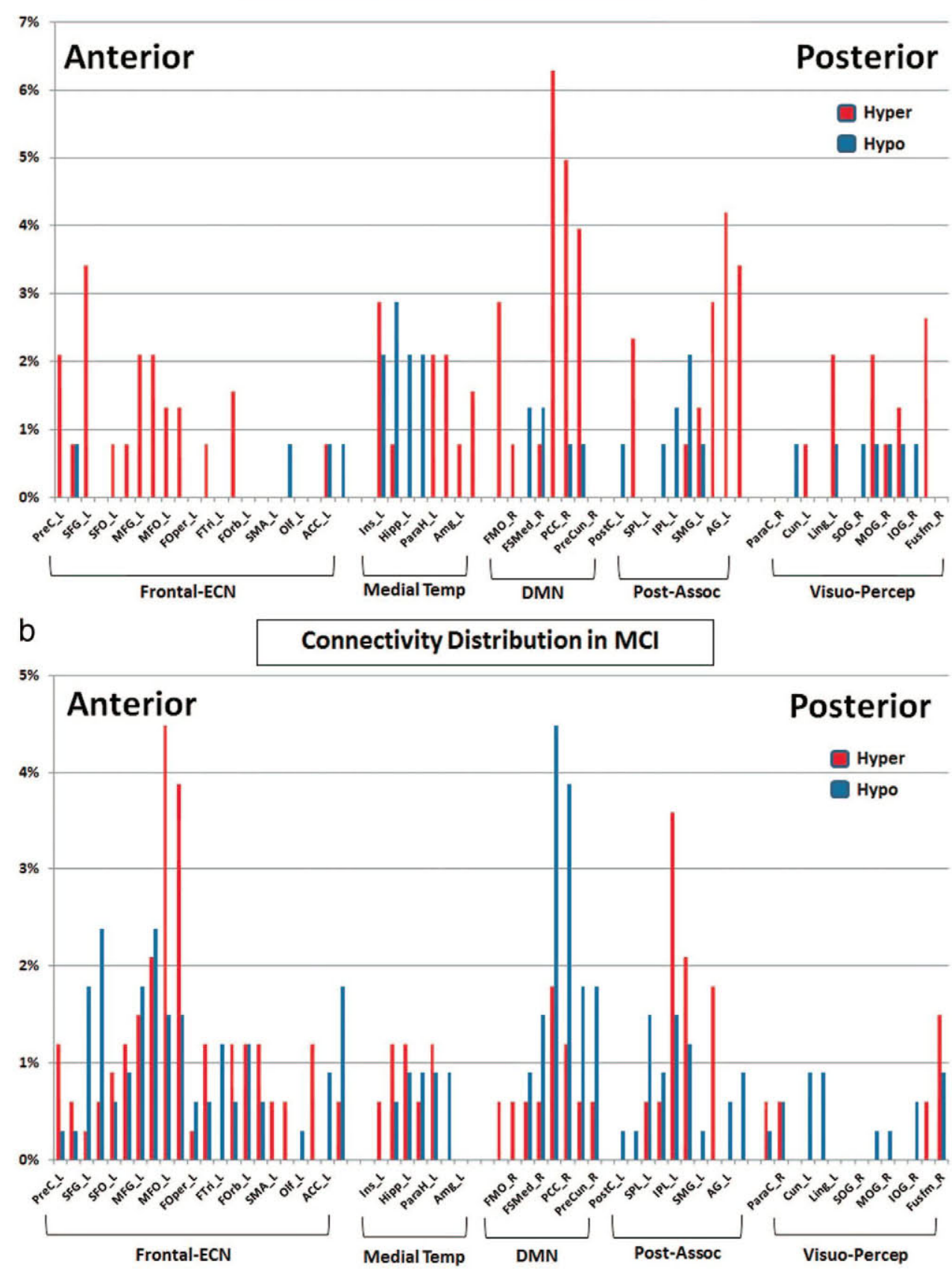

Figure 4. a-c abbreviations: For all; abbreviation $+\mathrm{L}=$ left; abbreviation $+\mathrm{R}=$ right. Moving left to right: $\mathrm{PreC}=$ precentral gyrus; $\mathrm{SFG}$; superior frontal gyrus; $\mathrm{SFO}=$ superior frontal orbital; $\mathrm{MFG}=$ middle frontal gyrus; $\mathrm{MFO}=$ middle frontal orbital; FOper $=$ frontal operculum; FTri $=$ frontal triangularis; Forb $=$ frontal orbitalis; SMA = supplementary motor area; Olf = olfactory; $\mathrm{ACC}=$ anterior cingulate cortex; Ins = insula; Hipp = hippocampus; $\mathrm{ParaH}=$ parahippocampal area; Amg = amygdala; $\mathrm{FMO}=$ frontal medial orbital; FSMed $=$ frontal superior medial; $\mathrm{PCC}=$ posterior cingulate cortex; PreCun $=$ precunues; PostC $=$ postcentral gyrus; $\mathrm{SPL}=$ superior parietal lobule; IPL $=$ inferior parietal lobule; $\mathrm{SMG}=$ supramarginal gyrus; $\mathrm{AG}=$ angular gyrus; ParaC $=$ paracentral gyrus; Cun = cuneus; Ling $=$ lingual gyrus; $\mathrm{SOG}=$ superior occipital gyrus; $\mathrm{MOG}=$ middle occipital gyrus; $\mathrm{IOG}=$ inferior occipital gyrus; Fusfm $=$ fusiform gyrus. The color version of this figure appears in the online article only. 


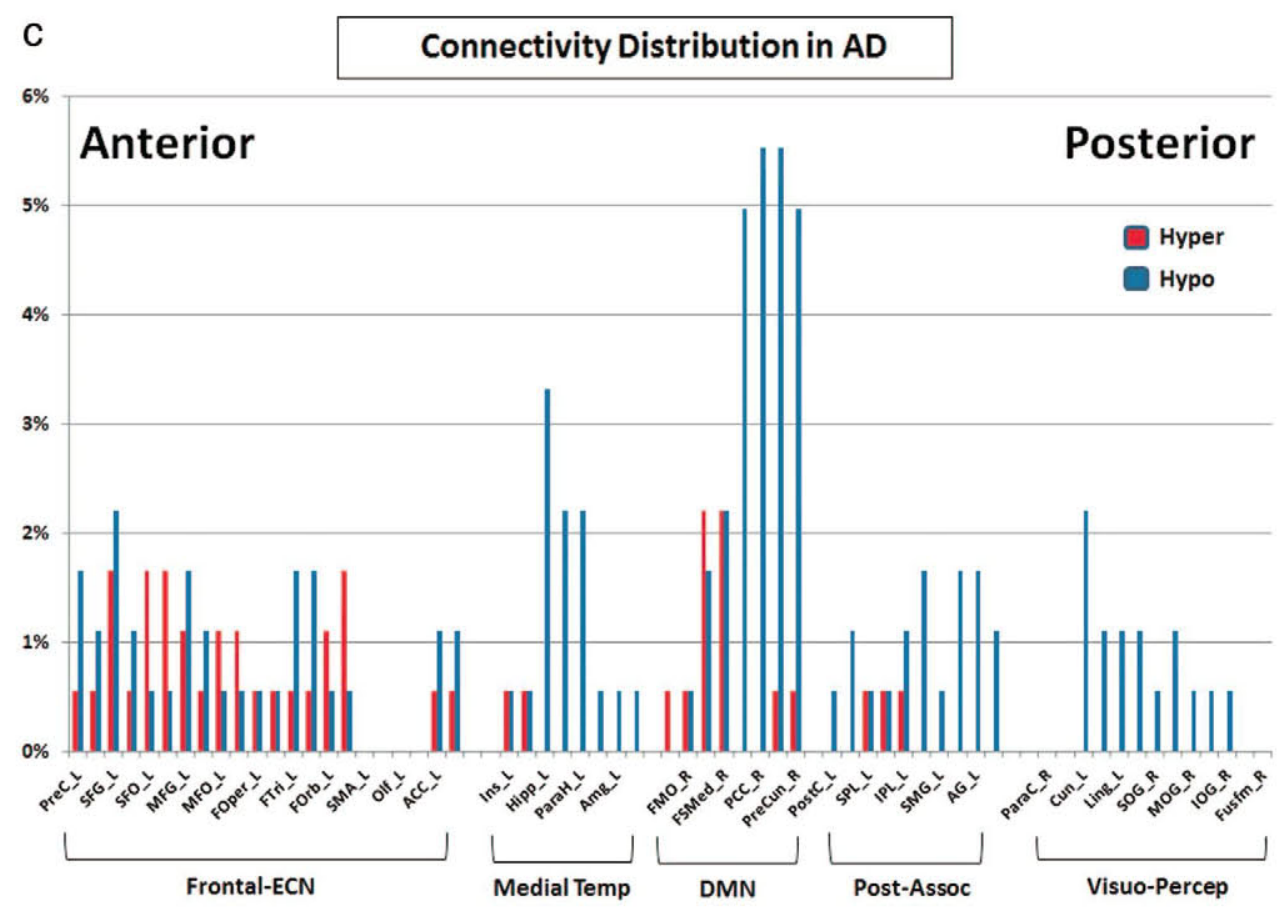

Figure 4 (continued)

may hold strong relationships to increased spiking output. Moreover, the hyperconnectivity observed in this review is largely consistent with clinical fMRI studies of mean signal change (amplitude) revealing neural recruitment in clinical samples (see Hillary, 2008; Hillary et al., 2006) and a relationship between signal amplitude and brain connectivity (see Au Duong et al., 2005; Ceccarelli et al., 2010; Kasahara et al., 2011; Sharp et al., 2011).

There is also evidence that measured changes in functional connectivity between ROIs in clinical samples may be a consequence not only of altered coupling between regions but also of increased heterogeneity in the signals within each ROI (Bassett et al., 2011; Zalesky et al., 2012). In schizophrenia, decreased pairwise regional functional connectivity has been found to strongly correlate with loss of intraregional homogeneity, increased variance, and decreased signal power (Bassett et al., 2011; Zalesky et al., 2012). Therefore, in regions directly influenced by pathology, increased intraregional decoherence directly constrains network connectivity properties (Bassett et al., 2011). These findings have been proposed as a mechanism for the observed connectivity loss in schizophrenia where local signal heterogeneity results in reduced covariance throughout distributed networks. Thus, connectivity loss can be traced to the effects of pathology on intra- and interregional signal homogeneity. Modeling these effects will be increasingly important in order to understand the influences of pathology on signal homogeneity both locally and globally.

One rarely addressed issue in current brain connectivity work has to do with the transience of brain connections or nonstationarity. Interesting recent work by Jones et al. (2012) examined the nonstationarity of pairwise relationships between nodes over the course of a time series. These authors demonstrate that in $\mathrm{AD}$, the "dwell time" in posterior DMN and anterior DMN configurations was a better indicator of network status and connectivity loss than the "steady state" connectivity magnitude. These findings are an important reminder that the typical measures of connectivity isolated in this literature capture only the most robust effects leaving unknown transient shifts in network connectivity. By modeling stochasticity in time series data (e.g., via sliding time windows) one can determine the timing and variability of observable connections to better understand how neural networks adapt to challenge and disruption (Gates \& Molenaar, 2012; Hillary et al., 2011a; Jones et al., 2012; Kiviniemi et al., 2011; Leonardi et al., 2013).

Another issue to consider when interpreting this literature focused on network connectivity has to do with how "connections" are neurally represented and their mechanism of action. With regard to the former, there is reason to believe that traditional node-to-node connectivity models may oversimplify neural systems. Binary models have been challenged in dynamical models revealing that communication between regions is likely probabilistic and at least partially determined by the readiness of neural inputs for oscillatory behavior (Buzsaki, 2004). In this sense, the BOLD signal measured in the studies reviewed here may be sensitive to the most robust and consistent oscillatory behaviors between regions. With respect to the mechanism of action in the connections observed in time series data, the BOLD signal cannot decipher between the various inputs including excitatory and inhibitory sources or recursive loops (Logothetis, 2008). There is little evidence in current computational modeling (e.g., activation gradients) that networks can operate solely in feed-forward fashion (Werfel, Xie, \& Seung, 2005), leaving unknown the combination of inhibitory versus excitatory inputs to any "connection" observed in the studies reviewed here. Therefore, the increased synchronization between regions can be interpreted as increased involvement of the network, but little can be said about the nature of that involvement. It should be noted that there is significant evidence in 
studies using electrophysiological methods (e.g., MEG, EEG) supporting the current findings in fMRI (see Castellanos et al., 2010; Stam et al., 2009; Stam et al., 2006; Stam et al., 2007; Tijms et al., 2013), so although neurovascular methods cannot clarify the nature of the neural activity, it is highly unlikely that the current findings can be explained as a vascular anomaly alone (e.g., decoupling between vascular and neuronal signaling).

\section{What Does Hyperconnectivity Achieve for Networks?}

We argue in this review that a common response to neurological disruption is hyperconnectivity and the literature demonstrates that when neural resources are available (e.g., TBI, MS), hyperconnectivity is not only possible, but likely. Although hyperconnectivity was a common finding, it is improbable that increased connectivity occurs in isolation; instead, some combination of connectivity gain and loss is expressed differentially throughout the network. For example, increased connectivity within local systems may be coupled with reduced long distance connections, or increased path length (e.g., Nakamura et al., 2009; Pandit et al., 2013; SanzArigita et al., 2010; Yao et al., 2010). Reduced information processing efficiency has been shown to be associated with increased global path length (van den Heuvel et al., 2009; Sporns, 2011b), and increased connectivity strength has implications for resource use (i.e., metabolism; Nakamura et al., 2009). Therefore, although increased connectivity may permit continued communication during periods of significant network disruption, this network response may also have two important side effects, observable as two of the most common behavioral consequences in neurological disorders: (a) slowed processing speed and (b) cognitive fatigue. Network modeling provides the unique opportunity to examine these relationships in future work.

The most common explanation for the hyperconnectivity response observed in this literature is that it is a compensatory response, where "compensation" is a nonspecific increase in neural resource use operating as a buffer against network disruption. Unfortunately, this explanation offers very little real clarification regarding the permanence of this network response or the success of these network changes with regard to behavior. Ultimately, what determines the connectivity changes in response to neurological distuption is likely to be multifactorial including (a) the brain state at the time of the measurement (see Buzsaki et al., 2004), (b) the role the affected nodes play in larger networks (e.g., hubs or the "rich club," see Harriger et al., 2012; van den Heuvel, Kahn, Goñi, \& Sporns, 2012), and (c) the availability of both local and global connections. For example, in $\mathrm{AD}$ the most common finding observed in the literature reviewed here was connectivity loss between frontal and posterior brain systems and this was evident even in the context of increased frontal connectivity. However, given the reliance of frontal systems on hippocampal and posterior networks in memory functioning (see Ranganath et al., 2005a), it is unclear that frontal hyperconnectivity successfully facilitates memory functioning (i.e., is compensatory). In fact, given that those pathways with the greatest metabolic demand may also be the most susceptible to AD-related pathology (see Buckner et al., 2005; Cirrito et al., 2005; Vlassenko et al., 2010), it remains to be demonstrated that hyperconnectivity within critical network hubs over time is indeed adaptive.
It is highly unlikely that all connectivity changes observed during periods of cerebral challenge serve identical functions; much additional work is needed to determine the mechanism and functional role for specific hyperconnectivity responses. For example, in the study of memory functioning we have hypothesized that hyperconnectivity after TBI provides the minimum resources required to meet task demands, but a consequence for recruitment is neural inefficiency and slowed information processing (see Hillary et al., 2010; Hillary et al., 2011a; Medaglia et al., 2012). We anticipate that these effects may be quite different from what is observed in MCI/DAT where the pathophysiology is distinct from TBI and there are very different behavioral consequences (i.e., amnesia vs. processing speed deficits). To date, neither the cause for hyperconnectivity nor its mechanism of action are entirely clear. We argue here that hyperconnectivity (a) is a basic response to insult, (b) may have competing implications for performance (e.g., increased demand on cognitive control resources permits task completion but with reduced efficiency), (c) is not linked to any specific pathophysiology, and (d) does not appear to be solely due to methodological artifact. To determine the specific function of hyperconnectivity in brain injury, it will be necessary to examine its evolution over different temporal and spatial scales with focus on determining the consequences for symptoms and recovery.

\section{Future Directions}

Although the data from studies sampled here support a hyperconnectivity hypothesis, certainly a broad review of this literature cannot be definitive in many respects. One limitation to our inclusive approach in sampling the connectivity literature is that the definition and measurement of "connectivity" shows some variation between studies, including distinct statistical procedures and networks of interest (e.g., whole brain vs. DMN). For example, in two of the studies of TBI showing reduced connectivity, the authors focused on isolated networks without examination of the consequences to large-scale connectivity (e.g., motor system only; connections only to the superior frontal gyrus). Even so, we do not anticipate any systematic bias that could change the results presented here; in fact, there was general consistency in the findings for both local and global networks studied.

This review does not include a comprehensive quantitative analysis, which was desirable but not possible given the data quality presented in typical connectivity studies. Most commonly comparative contrasts focus on the location and magnitude of between-groups differences (e.g., x, y, z coordinates, $F$ or $Z$ score) in the absence of providing the descriptive statistics for those differences. This appears to be an unfortunate carry-over from the signal amplitude (i.e., activation) literature where localization of BOLD differences over other features was the central focus. This review might serve as a reminder to investigators and reviewers that the connectivity values for each group (i.e., correlation values, means, standard deviation) should be included with all findings. Even in the absence of extensive quantification of the effects observed in these studies, this review of 126 articles provides the foundation for a more nuanced examination of specific comnectivity metrics in the future. In sum, the current review provides a summary of the use of connectivity modeling to examine macrolevel shifts in brain networks and there is support for the primary arguments that (a) hyperconnec- 
tivity is a common brain response to neurological disruption, and (b) the expression of hyperconnectivity is dependent upon pathology and resource availability. Much remains to be determined, including the basic mechanism(s) for hyperconnectivity and what this network response achieves for behavior. Future work should establish those transient/situational demands associated with hyperconnectivity and the physical resource thresholds that permit its expression.

\section{References}

References marked with an asterisk were used in the literature review. See the supplemental materials for further information.

${ }^{*}$ Agosta, F., Pievani, M., Geroldi, C., Copetti, M., Frisoni, G. B., \& Filippi, M. (2012). Resting state fMRI in Alzheimer's disease: Beyond the default mode network. Neurobiology of Aging, 33, 1564-1578. doi: 10.1016/j.neurobiolaging.2011.06.007

${ }^{*}$ Albert, R., \& Barabasi, A. L. (2002). Statistical methods of complex networks. Review of Modern Physics, 74, pp. 47-97. doi:10.1103/ RevModPhys. 74.47

Albert, R., Jeong, H., \& Barabasi, A. L. (2000). Error and attack tolerance of complex networks. Nature, 406, 378-382. doi:10.1038/35019019

${ }^{*}$ Allen, G., Barnard, H., McColl, R., Hester, A. L., Fields, J. A., Weiner, M. F., . . . Cullum, C. M. (2007). Reduced hippocampal functional connectivity in Alzheimer disease. Archives of Neurology, 64, 14821487. doi:10.1001/archneur.64.10.1482

Alves, J., Soares, J. M., Sampaio, A., \& Gonçalves, O. F. (2013). Posterior cortical atrophy and Alzheimer's disease: A meta-analytic review of neuropsychological and brain morphometry studies. Brain Imaging and Behavior. Advance online publication. doi:10.1007/s1 1682-013-9236-1

*Arenivas, A., Diaz-Arrastia, R., Spence, J., Cullum, C. M., Krishnan, K., Bosworth, C., . . Marquez de la Plata, C. (2012). Three approaches to investigating functional compromise to the default mode network after traumatic axonal injury. Brain Imaging and Behavior. Advance online publication. doi: $10.1007 / \mathrm{s} 11682-012-9191-2$

Arieli, A., Sterkin, A., Grinvald, A., \& Aertsen, A. (1996). Dynamics of ongoing activity: Explanation of the large variability in evoked cortical responses. Science, 273, 1868-1871. doi:10.1126/science. 273.5283 .1868

Au Duong, M. V., Audoin, B., Boulanouar, K., Ibarrola, D., Malikova, I., Confort-Gouny, S., . . . Ranjeva, J. P. (2005). Altered functional connectivity related to white matter changes inside the working memory network at the very early stage of MS. Journal of Cerebral Blood Flow and Metabolism, 25, 1245-1253. doi:10.1038/sj.jcbfm.9600122

*Au Duong, M. V., Boulanouar, K., Audoin, B., Treseras, S., Ibarrola, D., Malikova, I., . . . Ranjeva, J. P. (2005). Modulation of effective connectivity inside the working memory network in patients at the earliest stage of multiple sclerosis. Neurolmage, 24, 533-538. doi:10.1016/j .neuroimage.2004.08.038

${ }^{*}$ Bai, F., Liao, W., Watson, D. R., Shi, Y., Wang, Y., Yue, C., . . Zhang, $Z$. (2011c). Abnormal whole-brain functional connection in amnestic mild cognitive impairment patients. Behavioural Brain Research, 20, $666-672$.

${ }^{*}$ Bai, F., Liao, W., Watson, D. R., Shi, Y., Yuan, Y., Cohen, A. D., . . . Zhang, Z. (2011b). Mapping the altered patterns of cerebellar restingstate function in longitudinal amnestic mild cognitive impairment patients. Journal of Alzheimer's Disease, 23, 87-99.

${ }^{*}$ Bai, F., Shi, Y., Yuan, Y., Wang, Y., Yue, C., Teng, Y., . . . Zhang, Z. (2012). Altered self-referential network in resting-state amnestic type mild cognitive impairment. Cortex, 48, 604-613. doi:10.1016/j.cortex .2011 .02 .011

${ }^{*}$ Bai, F., Watson, D. R., Shi, Y., Wang, Y., Yue, C., YuhuanTeng, D. W., . . Zhang, Z. (2011a). Specifically progressive deficits of brain functional marker in amnestic type mild cognitive impairment. PLOS ONE, 6 , e24271. doi: $10.1371 /$ journal.pone.0024271
${ }^{*}$ Bai, F., Watson, D. R., Yu, H., Shi, Y., Yuan, Y., \& Zhang, Z. (2009). Abnormal resting-state functional connectivity of posterior cingulate cortex in amnestic type mild cognitive impairment. Brain Research, 1302, 167-174. doi:10.1016/j.brainres.2009.09.028

${ }^{*}$ Bai, F., Zhang, Z., Watson, D. R., Yu, H., Shi, Y., Yuan, Y., . . Qian, Y. (2009). Abnormal functional connectivity of hippocampus during episodic memory retrieval processing network in amnestic mild cognitive impairment. Biological Psychiatry, 65, 951-958. doi:10.1016/j.biopsych 2008.10 .017

${ }^{*}$ Bai, F., Zhang, Z., Yu, H., Shi, Y., Yuan, Y., Zhu, W., . . Qian, Y. (2008). Default-mode network activity distinguishes amnestic type mild cognitive impairment from healthy aging: A combined structural and restingstate functional MRI study. Neuroscience Letters, 438, 111-115. doi: 10.1016/j.neulet.2008.04.021

${ }^{*}$ Balthazar, M. L., Pereira, F. R., Lopes, T. M., da Silva, E. L., Coan, A. C., Campos, B. M., . . . Cendes, F. (2013). Neuropsychiatric symptoms in Alzheimer's disease are related to functional connectivity alterations in the salience network. Human Brain Mapping, 35, 1237-1246.

Bassett, D. S., Wymbs, N. F., Porter, M. A., Mucha, P. J., Carlson, J. M., \& Grafton, S. T. (2011). Dynamic reconfiguration of human brain networks during learning. Proceedings of the National Academy of Sciences of the United States of America, 108, 7641-7646. doi:10.1073/ pnas. 1018985108

${ }^{\text {*}}$ Binnewijzend, M. A., Schoonheim, M. M., Sanz-Arigita, E., Wink, A. M., van der Flier, W. M., Tolboom, N., . . Barkhof, F. (2012). Resting-state fMRI changes in Alzheimer's disease and mild cognitive impairment. Neurobiology of Aging, 33, 2018-2028. doi:10.1016/j.neurobiolaging .2011 .07 .003

Biswal, B. B., Mennes, M., Zuo, X. N., Gohel, S., Kelly, C., Smith, S. M., .. Milham, M. P. (2010). Toward discovery science of human brain function. Proceedings of the National Academy of Sciences of the United States of America, 9, 4734-4739.

${ }^{*}$ Biswal, B., Yetkin, F. Z., Haughton, V. M., \& Hyde, J. S. (1995). Functional connectivity in the motor cortex of resting human brain using echo-planar MRI. Magnetic Resonance in Medicine, 34, 537-541. doi 10.1002/mrm. 1910340409

${ }^{*}$ Bokde, A. L., Lopez-Bayo, P., Meindl, T., Pechler, S., Born, C., Faltraco, F., ... Hampel, H. (2006). Functional connectivity of the fusiform gyrus during a face-matching task in subjects with mild cognitive impairment. Brain, 129, 1113-1124. doi:10.1093/brain/aw1051

${ }^{*}$ Bonavita, S., Gallo, A., Sacco, R., Corte, M. D., Bisecco, A., Docimo, R., .. . Tedeschi, G. (2011). Distributed changes in default-mode restingstate connectivity in multiple sclerosis. Multiple Sclerosis, 17, 411-422. doi: $10.1177 / 1352458510394609$

Bonnelle, V., Ham, T. E., Leech, R., Kinnunen, K. M., Mehta, M. A., Greenwood, R. J., \& Sharp, D. J. (2012). Salience network integrity predicts default mode network function after traumatic brain injury. Proceedings of the National Academy of Sciences of the United States of America, 109, 4690-4695. doi:10.1073/pnas.1113455109

Bonnelle, V., Leech, R., Kinnunen, K. M., Ham, T. E., Beckmann, C. F., De Boissezon, X., . . . Sharp, D. J. (2011). Default mode network connectivity predicts sustained attention deficits after traumatic brain injury. The Journal of Neuroscience, 31(38), 13442-51. doi:10.1523/ JNEUROSCI.1163-11.2011

${ }^{*}$ Braak, H., \& Braak, E. (1991). Neuropathological staging of Alzheimerrelated changes. Acta Neuropathologica, 82, 239-259.

Buckner, R. L., Snyder, A. Z., Shannon, B. J., LaRossa, G., Sachs, R., Fotenos, A. F., et al. (2005). Molecular, structural, and functional characterization of Alzheimer's disease: Evidence for a relationship between default activity, amyloid, and memory. The Journal of Neuro science, 25, 7709-7717. doi:10.1523/JNEUROSCI.2177-05.2005

Buzsaki, G. (2004). Large-scale recording of neuronal ensembles. Nature Neuroscience, 7, 446-451. doi:10.1038/nn1233 
${ }^{*}$ Cader, S., Cifelli, A., Abu-Omar, Y., Palace, J., \& Matthews, P. M. (2006). Reduced brain functional reserve and altered functional connectivity in patients with multiple sclerosis. Brain, 129, 527-537. doi: $10.1093 / \mathrm{brain} / \mathrm{awh} 670$

${ }^{*}$ Caeyenberghs, K., Leemans, A., Heitger, M. H., Leunissen, I., Dhollander, T., Sunaert, S., . . Swinnen, S. P. (2012). Graph analysis of functional brain networks for cognitive control of action in traumatic brain injury. Brain, 135, 1293-1307. doi:10.1093/brain/aws048

${ }^{*}$ Canuet, L., Tellado, I., Couceiro, V., Fraile, C., Fernandez-Novoa, L., Ishii, R., . . Cacabelos, R. (2012). Resting-state network disruption and APOE genotype in Alzheimer's disease: A lagged functional connectivity study. PLOS ONE, 7, e46289. doi:10.1371/journal.pone.0046289

${ }^{*}$ Casanova B., Martínez-Bisbal, M. C., Valero, C., Celda, B., MartíBonmatí, L., Pascual, A., . . Coret, F. (2003). Evidence of Wallerian degeneration in normal appearing white matter in the early stages of relapsing-remitting multiple sclerosis. Journal of Neurology, 250, 2228. doi:10.1007/s00415-003-0928-0

Castellanos, N. P., Paúl, N., Ordóñez, V. E., Demuynck, O., Bajo, R., Campo, P., . . . Maestú F. (2010). Reorganization of functional connectivity as a correlate of cognitive recovery in acquired brain injury. Brain, 133, 2365-2381. doi:10.1093/brain/awq174

Ceccarelli, A., Rocca, M. A., Valsasina, P., Rodegher, M., Falini, A., Comi, G., \& Filippi, M. (2010). Structural and functional magnetic resonance imaging correlates of motor network dysfunction in primary progressive multiple sclerosis. European Journal of Neuroscience, 31 , 1273-1280. doi: 10.1111/j.1460-9568.2010.07147.x

*Cerasa, A., Passamonti, L., Valentino, P., Nisticò, R., Pirritano, D., Gioia, M. C., . . Quattrone, A. (2012). Cerebellar-parietal dysfunctions in multiple sclerosis patients with cerebellar signs. Experimental Neurology, 237, 418-426. doi:10.1016/j.expneurol.2012.07.020

Chawla, D., Lumer, E. D., \& Friston, K. J. (1999). The relationship between synchronization among neuronal populations and their mean activity levels. Neural Computation, 11, 1389-1411. doi:10.1162/ 089976699300016287

Chawla, D., Lumer, E. D., \& Friston, K. J. (2000). Relating macroscopic measures of brain activity to fast, dynamic neuronal interactions. Neural Computation, 12, 2805-2821. doi:10.1162/089976600300014737

${ }^{*}$ Chen, G., Zhang, H. Y., Xie, C., Chen, G., Zhang, Z. J., Teng, G. J., \& Li, S. J. (2013). Modular reorganization of brain resting state networks and its independent validation in Alzheimer's disease patients. Frontiers in Human Neuroscience, 7, 456. doi:10.3389/fnhum.2013.00456 .eCollection2013

${ }^{*}$ Chhatwal, J. P., Schultz, A. P., Johnson, K., Benzinger, T. L., Jack, C.Jr., Ances, B. M., . . . Sperling, R. A. (2013). Impaired default network functional connectivity in autosomal dominant Alzheimer disease. Neurology, 81, 736-744. doi:10.1212/WNL.0b013e3182a1aafe

${ }^{*}$ Ciftçi, K. (2011). Minimum spanning tree reflects the alterations of the default mode network during Alzheimer's disease. Annals of Biomedical Engineering, 39, 1493-1504. doi:10.1007/s10439-011-0258-9

Cirrito, J. R., Yamada, K. A., Finn, M. B., Sloviter, R. S., Bales, K. R., May, P. C., et al. (2005). Synaptic activity regulates interstitial fluid amyloid-beta levels in vivo. Neuron, 48, 913-922. doi:10.1016/j.neuron .2005 .10 .028

${ }^{*}$ Codecà, C., Mori, F., Kusayanagi, H., Monteleone, F., Boffa, L., Paolillo, A., Bernardi, G., . . . Centonze, D. (2010). Differential patterns of interhemispheric functional disconnection in mild and advanced multiple sclerosis. Multiple Sclerosis, 16, 1308-1316. doi:10.1177/ 1352458510376957

${ }^{*}$ Cole, L. J., Gavrilescu, M., Johnston, L. A., Gibson, S. J., Farrell, M. J., \& Egan, G. F. (2011). The impact of Alzheimer's disease on the functional connectivity between brain regions underlying pain perception. European Journal of Pain, 15, e1-e11.

Damasio, A. R., \& Galaburda, A. (1985). Norman Geschwind. Archives of Neurology, 42, 500-504. doi:10.1001/archneur.1985.04060050102019
${ }^{*}$ Damoiseaux, J. S., Prater, K. E., Miller, B. L., \& Greicius, M. D. (2012) Functional connectivity tracks clinical deterioration in Alzheimer's disease. Neurobiology of Aging, 33, e19-e30.

${ }^{*}$ Das, S. R., Pluta, J., Mancuso, L., Kliot, D., Orozco, S., Dickerson, B. C., ... Wolk, D. A. (2013). Increased functional connectivity within medial temporal lobe in mild cognitive impairment. Hippocampus, 23(1), 1-6. doi:10.1002/hipo.22051

Demaree, H. A., et al. (1999). Speed of information processing as a key deficit in multiple sclerosis: Implications for rehabilitation. Journal of Neurology, Neurosurgery, \& Psychiatry, 67, 661-663. doi:10.1136/jnnp .67.5.661

${ }^{*}$ Dogonowski, A. M., Siebner, H. R., Soelberg Sørensen, P., Paulson, O. B., Dyrby, T. B., Blinkenberg, M., \& Madsen, K. H. (2013). Restingstate connectivity of pre-motor cortex reflects disability in multiple sclerosis. Acta Neurologica Scandinavica, 128, 328-335. doi:10.1111/ ane. 12121

${ }^{*}$ Dogonowski, A. M., Siebner, H. R., Sørensen, P. S., Wu, X., Biswal, B., Paulson, O. B., . . Madsen, K. H. (2013). Expanded functional coupling of subcortical nuclei with the motor resting-state network in multiple sclerosis. Multiple Sclerosis, 19, 559-566.

Dolcos, F., Rice, H. J., \& Cabeza, R. (2002). Hemispheric asymmetry and aging: Right hemisphere decline or asymmetry reduction. Neuroscience and Biobehavioral Reviews, 26, 819-825. doi:10.1016/S01497634(02)00068-4

${ }^{*}$ Dong, L., Shen, Y., Lei, X., Luo, C., Li, Q. W., Wu, W. Y., . . Li, C. B. (2012). The heterogeneity of aging brain: Altered functional connectivity in default mode network in older adults during verbal fluency tests. Chinese Medical Journal, 125, 604-610.

${ }^{*}$ Drzezga, A., Becker, J. A., Van Dijk, K. R., Sreenivasan, A., Talukdar, T., Sullivan, C., . . Sperling, R. A. (2011). Neuronal dysfunction and disconnection of cortical hubs in non-demented subjects with elevated amyloid burden. Brain, 134, 1635-1646. doi:10.1093/brain/awr066

${ }^{*}$ Esposito, R., Mosea, A., Pieramico, V., Cieri, F., Cera, N., \& Sensi, S. L. (2013). Characterization of resting state activity in MCI individuals. PeerJ, 20, e135.

${ }^{*}$ Faivre, A., Rico, A., Zaaraoui, W., Crespy, L., Reuter, F., Wybrecht, D., Soulier, E., . . Audoin, B. (2012). Assessing brain connectivity at rest is clinically relevant in early multiple sclerosis. Multiple Sclerosis, 18 , 1251-1258. doi: $10.1177 / 1352458511435930$

${ }^{*}$ Feng, Y., Bai, L., Ren, Y., Chen, S., Wang, H., Zhang, W., \& Tian, J. (2012). fMRI connectivity analysis of acupuncture effects on the whole brain network in mild cognitive impairment patients. Magnetic Resonance Imaging, 30, 672-682. doi:10.1016/j.mri.2012.01.003

${ }^{\text {F}}$ Forn, C., Rocca, M. A., Valsasina, P., Boscá I., Casanova, B., Sanjuan, A., Filippi, M. (2012). Functional magnetic resonance imaging correlates of cognitive performance in patients with a clinically isolated syndrome suggestive of multiple sclerosis at presentation: An activation and connectivity study. Multiple Sclerosis, 18, 153-163. doi:10.1177. 1352458511417744

Fox, M. D., Snyder, A. Z., Vincent, J. L., Corbetta, M., Van Essen, D. C., \& Raichle, M. E. (2005). The human brain is intrinsically organized into dynamic, anticorrelated functional networks. Proceedings of the $\mathrm{Na}$ tional Academy of Sciences of the United States of America, 102, 9673-9678. doi: 10.1073/pnas.0504136102

${ }^{*}$ Franciotti, R., Falasca, N. W., Bonanni, L., Anzellotti, F., Maruotti, V., Comani, S., . . Onofrj, M. (2013). Default network is not hypoactive in dementia with fluctuating cognition: An Alzheimer disease/dementia with Lewy bodies comparison. Neurobiology of Aging, 34, 1148-1158. doi:10.1016/j.neurobiolaging.2012.09.015

${ }^{\text {F}}$ Gallo, A., Esposito, F., Sacco, R., Docimo, R., Bisecco, A., Della Corte, M., . . Tedeschi, G. (2012). Visual resting-state network in relapsingremitting MS with and without previous optic neuritis. Neurology, 79, $1458-1465$. 
${ }^{*}$ Galvin, J. E., Price, J. L., Yan, Z., Morris, J. C., \& Sheline, Y. I. (2012). Resting bold fMRI differentiates dementia with Lewy bodies vs. Alzheimer disease. Neurology, 76, 1797-1803.

Gates, K. M., \& Molenaar, P. C. (2012). Group search algorithm recovers effective connectivity maps for individuals in homogeneous and heterogeneous samples. NeuroImage, 63, 310-319. doi:10.1016/j.neuroimage.2012.06.026

Gazzaniga, M. S., \& Smylie, C. S. (1984). Dissociation of language and cognition. (1984). A psychological profile of two disconnected right hemispheres. Brain, 107, 145-153. doi:10.1093/brain/107.1.145

Gazzaniga, M. S., Volpe, B. T., Smylie, C. S., Wilson, D. H., \& LeDoux, J. E. (1979). Plasticity in speech organization following commissurotomy. Brain, 102, 805-815. doi:10.1093/brain/102.4.805

${ }^{*}$ Genon, S., Collette, F., Feyers, D., Phillips, C., Salmon, E., \& Bastin, C. (2012). Item familiarity and controlled associative retrieval in Alzheimer's disease: An fMRI study. Cortex, 49, 1566-1584.

Geschwind, N. (1965a). Disconnexion syndromes in animals and man. I. Brain, 88, 237-294. doi:10.1093/brain/88.2.237

Geschwind, N. (1965b). Disconnexion syndromes in animals and man. II. Brain, 88, 585-644. doi:10.1093/brain/88.3.585

${ }^{*}$ Gili, T., Cercignani, M., Serra, L., Perri, R., Giove, F., Maraviglia, B., .. . Bozzali, M. (2011). Regional brain atrophy and functional disconnection across Alzheimer's disease evolution. Journal of Neurology, Neurosurgery \& Psychiatry, 82, 58-66. doi:10.1136/jnnp.2009.199935

${ }^{*}$ Gour, N., Ranjeva, J. P., Ceccaldi, M., Confort-Gouny, S., Barbeau, E., Soulier, E., . . F Felician, O. (2011). Basal functional connectivity within the anterior temporal network is associated with performance on declarative memory tasks. Neurolmage, 58, 687-697. doi:10.1016/j .neuroimage.2011.05.090

${ }^{*}$ Grady, C. L., Furey, M. L., Pietrini, P., Horwitz, B., \& Rapoport, S. I. (2001). Altered brain functional connectivity and Impaired short-term memory in Alzheimer's disease. Brain, 124, 739-756. doi:10.1093/ brain/124.4.739

Greer, J. E., McGinn, M. J., \& Povlishock, J. T. (2011). Diffuse traumatic axonal injury in the mouse induces atrophy, activation, and axonal outgrowth in the axotomized neuronal population. The Journal of Net roscience, 31, 5089-5105. doi:10.1523/JNEUROSCI.5103-10.2011

${ }^{*}$ Greicius, M. D., Srivastava, G., Reiss, A. L., \& Menon, V. (2004). Default-mode network activity distinguishes Alzheimer's disease from healthy aging: Evidence from functional MRI. Proceedings of the National Academy of Sciences of the United States of America, 101, 4637-4642. doi:10.1073/pnas.0308627101

${ }^{*}$ Han, S. D., Arfanakis, K., Fleischman, D. A., Leurgans, S. E., Tuminello, E. R., Edmonds, E. C., \& Bennett, D. A. (2012). Functional connectivity variations in mild cognitive impairment: Associations with cognitive function. Journal of the International Neuropsychological Society, 18 , 39-48. doi:10.1017/S1355617711001299

${ }^{*}$ Hardmeier, M., Schoonheim, M. M., Geurts, J. J., Hillebrand, A., Polman, C. H., Barkhof, F., \& Stam, C. J. (2012). Cognitive dysfunction in early multiple sclerosis: Altered centrality derived from resting-state functional connectivity using magneto-encephalography. PLOS ONE, 7 , e42087. doi: 10.1371 journal.pone. 0042087

Harriger, L., van den Heuvel, M. P., \& Sporns, O. (2012). Rich club organization of macaque cerebral cortex and its role in network communication. PLOS ONE, 7, e46497. doi:10.1371/journal.pone.0046497

${ }^{*}$ Hawellek, D. J., Hipp, J. F., Lewis, C. M., Corbetta, M., \& Engel, A. K. (2011). Increased functional connectivity indicates the severity of cognitive impairment in multiple sclerosis. Proceedings of the National Academy of Sciences of the United States of America, 108, 19066 19071. doi:10.1073/pnas. 1110024108

${ }^{*}$ Helekar, S. A., Shin, J. C., Mattson, B. J., Bartley, K., Stosic, M., Saldana-King, T., . . Hutton, G. J. (2010). Functional brain network changes associated with maintenance of cognitive function in multiple sclerosis. Frontiers in Human Neuroscience, 4, 219. doi:10.3389/fnhum 2010.00219

Hillary, F. G. (2008). Neuroimaging of working memory dysfunction and the dilemma with brain reorganization hypotheses. Journal of the Inter national Neuropsychological Society, 14, 526-534. doi:10.1017/ S1355617708080788

Hillary, F. G., Genova, H. M., Medaglia, J. D., Fitzpatrick, N. M., Chiou, K. S., Wardecker, B. M., \& DeLuca, J. (2010). The nature of processing speed deficits in traumatic brain injury: Is less brain more? Brain Imaging Behavior, 4, 141-154. doi:10.1007/s11682-010-9094-Z

Hillary, F. G., Genova, H. M., Chiaravalloti, N. D., Rypma, B., \& DeLuea, J. (2006). Prefrontal modulation of working memory performance in brain injury and disease. Human Brain Mapping, 27, 837-847. doi: $10.1002 / \mathrm{hbm} .20226$

Hillary, F. G., Medaglia, J. D., Gates, K., Molenaar, P. C., Slocomb, J., Peechatka, A., \& Good, D. C. (2011a). Examining working memory task acquisition in a disrupted neural network. Brain, 134, 1555-1570. doi: $10.1093 /$ brain/awr043

${ }^{*}$ Hillary, F. G., Slocomb, J., Hills, E. C., Fitzpatrick, N. M., Medaglia, J. D., Wang, J., . . Wylie, G. R. (2011b). Changes in resting connectivity during recovery from severe traumatic brain injury. International Journal of Psychophysiology, 82, 115-123. doi:10.1016/j.ijpsycho.2011 .03 .011

Hillebrand, A., Barnes, G. R., Bosboom, J. L., Berendse, H. W., Stam, C. J. (2012). Frequency-dependent functional connectivity within restingstate networks: an atlas-based MEG beamformer solution. Neuroimage, 15;59(4):3909-21.

Hou, R., Moss-Morris, R., Peveler, R., Mogg, K., Bradley, B. P., \& Belli, A. (2012). When a minor head injury results in enduring symptoms: A prospective investigation of risk factors for postconcussional syndrome after mild traumatic brain injury. Journal of Neurology, Neurosurgery \& Psychiatry, 83, 217-223. doi:10.1136/jnnp-2011-300767

${ }^{*}$ Huang, S., Li, J., Sun, L., Ye, J., Fleisher, A., Wu, T., Chen, K., \& Reiman, E. (2010). Learning brain connectivity of Alzheimer's disease by sparse inverse covariance estimation. Neurolmage, 50, 935-949. doi:10.1016/j.neuroimage.2009.12.120

${ }^{*} J a c k$, C. R., Jr., Knopman, D. S., Jagust, W. J., Shaw, L. M., Aisen, P. S., Weiner, M. W., . . Trojanowski, J. Q. (2010). Hypothetical model of dynamic biomarkers of the Alzheimer's pathological cascade. Lancet Neurology, 9, 119-128.

${ }^{*}$ Jacobs, H. I., Van Boxtel, M. P., Heinecke, A., Gronenschild, E. H., Backes, W. H., Ramakers, I. H., . . Verhey, F. R. (2012). Functional integration of parietal lobe activity in early Alzheimer disease. Neurology, 78, 352-360. doi: 10.1212/WNL.0b013e318245287d

${ }^{*}$ Jiang, X., Zhu, D., Li, K., Zhang, T., Wang, L., Shen, D., . . Liu, T. (2013). Predictive models of resting state networks for assessment of altered functional connectivity in mild cognitive impairment. Brain Imaging and Behavior, 2013 Dec 1.

${ }^{*}$ Jin, M., Pelak, V. S., \& Cordes, D. (2012). Aberrant default mode network in subjects with amnestic mild cognitive impairment using resting-state functional MRI. Magnetic Resonance Imaging, 30, 48-61. doi:10.1016/ j.mri.2011.07.007

${ }^{*} J o n e s$, D. T., Machulda, M. M., Vemuri, P., McDade, E. M., Zeng, G., Senjem, M. L., . . Jack, C. R., Jr. (2011). Age-related changes in the default mode network are more advanced in Alzheimer's disease. Neurology, $18,77,1524-1531$.

${ }^{*} J o n e s$, D. T., Vemuri, P., Murphy, M. C., Gunter, J. L., Senjem, M. L., Machulda, M. M., . . . Jack, C. R., Jr. (2012). Non-stationarity in the "resting brain's" modular architecture. PLoS ONE, 7, e39731. doi: 10.1371/journal.pone.0039731

Kasahara, M., Menon, D. K., Salmond, C. H., Outtrim, J. G., Tavares, J. V., Carpenter, T. A., . . Stamatakis, E. A. (2011). Traumatic brain injury alters the functional brain network mediating working memory. Brain Injury, 25, 1170-1187. doi:10.3109/02699052.2011.608210 
"Kasahara, M., Menon, D. K., Salmond, C. H., Outtrim, J. G., Taylor Tavares, J. V., Carpenter, T. A., . . Stamatakis, E. A. (2010). Altered functional connectivity in the motor network after traumatic brain injury. Neurology, 75, 168-176. doi:10.1212/WNL.0b013e3181e7ca58

${ }^{*}$ Kato, T., Nakayama, N., Yasokawa, Y., Okumura, A., Shinoda, J., \& Iwama, T. (2007). Statistical image analysis of cerebral glucose metabolism in patients with cognitive impairment following diffuse traumatic brain injury. Journal of Neurotrauma, 24, 919-926. doi:10.1089/neu .2006 .0203

${ }^{*}$ Kim, J., Kim, Y. H., \& Lee, J. H. (2013). Hippocampus-precuneus functional connectivity as an early sign of Alzheimer's disease: A preliminary study using structural and functional magnetic resonance imaging data. Brain Research, 1495, 18-29. doi:10.1016/j.brainres. 2012 .12 .011

Kiviniemi, V., Vire, T., Remes, J., Elseoud, A. A., Starck, T., Tervonen, O., \& Nikkinen, J. (2011). A sliding time-window ICA reveals spatial variability of the default mode network in time. Brain Connect, 1 , 339-347. doi:10.1089/brain.2011.0036

"Leavitt, V. M., Wylie, G., Genova, H. M., Chiaravalloti, N. D., \& DeLuca, J. (2012). Altered effective connectivity during performance of an information processing speed task in multiple sclerosis. Multiple Sclerosis, 18, 409-417. doi:10.1177/1352458511423651

${ }^{*}$ Leavitt, V. M., Wylie, G. R., Girgis, P. A., Deluca, J., \& Chiaravalloti, N. D. (2012). Increased functional connectivity within memory networks following memory rehabilitation in multiple sclerosis. Brain Imaging and Behavior. Advance online publication. doi:10.1007/s11682-0129183-2

${ }^{*}$ Li, R., Wu, X., Chen, K., Fleisher, A. S., Reiman, E. M., \& Yao, L. (2013). Alterations of directional connectivity among resting-state networks in Alzheimer disease. American Journal of Neuroradiology, 34, 340-345. doi:10.3174/ajnr.A3197

${ }^{7}$ Li, R., Wu, X., Fleisher, A. S., Reiman, E. M., Chen, K., \& Yao, L. (2012). Attention-related networks in Alzheimer's disease: A resting functional MRI study. Human Brain Mapping, 33, 1076-1088. doi: $10.1002 / \mathrm{hbm} .21269$

${ }^{*}$ Li, R., Yu, J., Zhang, S., Bao, F., Wang, P., Huang, X., \& Li, J. (2013). Bayesian network analysis reveals alterations to default mode network connectivity in individuals at risk for Alzheimer's disease. PLOS ONE, 8 , e82104.

${ }^{*}$ Liang, P., Wang, Z., Yang, Y., Jia, X., \& Li, K. (2011). Functional disconnection and compensation in mild cognitive impairment: Evidence from DLPFC connectivity using resting-state fMRI. PLOS ONE, 6 , e22153. doi: 10.1371/journal.pone.0022153

${ }^{\text {N}}$ Liang, P., Wang, Z., Yang, Y., \& Li, K. (2012). Three subsystems of the inferior parietal cortex are differently affected in mild cognitive impairment. Journal of Alzheimer's Disease, 30, 475-487.

${ }^{7}$ Liu, Y., Yu, C., Zhang, X., Liu, J., Duan, Y., Alexander-Bloch, A. F., . . Bullmore, E. (2013). Impaired long distance functional connectivity and weighted network architecture in Alzheimer's disease. Cerebral Cortex, $24,1422-1435$

${ }^{*}$ Liu, Z., Bai, L., Dai, R., Zhong, C., Wang, H., You, Y., . . Tian, J. (2012). Exploring the effective connectivity of resting state networks in mild cognitive impairment: An fMRI study combining ICA and multivariate Granger causality analysis. Conference Proceedings, 2012, 5454-5457.

${ }^{*}$ Liu, Z., Zhang, Y., Bai, L., Yan, H., Dai, R., Zhong, C., . . . Tian, J. (2012). Investigation of the effective connectivity of resting state networks in Alzheimer's disease: A functional MRI study combining independent components analysis and multivariate Granger causality analysis. NMR in Biomedicine, 25, 1311-1320. doi:10.1002/nbm.2803

Leonardi, N., Richiardi, J., Gschwind, M., Simioni, S., Annoni, J. M., Schluep, M., Vuilleumier, P., Van De Ville, D. (2013 dec). Principal components of functional connectivity: a new approach to study dynamic brain connectivity during rest. Neuroimage. $83,937-950$.
${ }^{*}$ Logothetis, N. K. (2008). What we can do and what we cannot do with fMRI. Nature. 2, 453, 869-878. doi:10.1038/nature06976. Review

${ }^{*}$ Loitfelder, M., Filippi, M., Rocca, M., Valsasina, P., Ropele, S., Jehna, M., . . Enzinger, C. (2012). Abnormalities of resting state functional connectivity are related to sustained attention deficits in MS. PLOSONE, 7, e42862. doi:10.1371/journal.pone.0042862

${ }^{\text {N} L o w e, ~ M . ~ J ., ~ B e a l l, ~ E . ~ B ., ~ S a k a i e, ~ K . ~ E ., ~ K o e n i g, ~ K . ~ A ., ~ S t o n e, ~ L ., ~ M a r r i e, ~}$ R. A., \& Phillips, M. D. (2008). Resting state sensorimotor functional connectivity in multiple selerosis inversely correlates with transcallosal motor pathway transverse diffusivity. Human Brain Mapping, 29, 818827. doi: $10.1002 / \mathrm{hbm} .20576$

${ }^{*}$ Lowe, M. J., Phillips, M. D., Lurito, J. T., Mattson, D., Dzemidzic, M., \& Mathews, V. P. (2002). Multiple sclerosis: Low-frequency temporal blood oxygen level-dependent fluctuations indicate reduced functional connectivity initial results. Radiology, 224, 184-192. doi:10.1148/radiol .2241011005

Luck, S. J., Hillyard, S. A., Mangun, G. R., \& Gazzaniga, M. S. (1989). Independent hemispheric attentional systems mediate visual search in split-brain patients. Nature, 342, 543-545. doi:10.1038/342543a0

${ }^{*}$ Marquez de la Plata, C. D., Garces, J., Shokri Kojori, E., Grinnan, J., Krishnan, K., Pidikiti, R., . . . Diaz-Arrastia, R. (2011). Deficits in functional connectivity of hippocampal and frontal lobe circuits after traumatic axonal injury. Archives of Neurology, 68, 74-84. doi:10.1001 archneurol.2010.342

Medaglia, J. D., Chiou, K. S., Slocomb, J., Fitzpatrick, N. M., Wardecker, B. M., Ramanathan, D., . . Hillary, F. G. (2012). The less BOLD, the wiser: Support for latent resource hypothesis after neurotrauma. Human Brain Mapping, 33, 979-993.

${ }^{*}$ Mesulam, M. M. (1985). Patterns in behavioral neuroanatomy: Association areas, the limbic system and hemispheric specialisation. In M. Mesulam (Ed.), Principles of behavioral neurology (pp. 1-70). Philadelphia, PA: F. A. Davis Co.

${ }^{*}$ Miao, X., Wu, X., Li, R., Chen, K., \& Yao, L. (2011). Altered connectivity pattern of hubs in default-mode network with Alzheimer's disease An Granger causality modeling approach. PLOS ONE, 6, e25546. doi 10.1371/journal.pone. 0025546

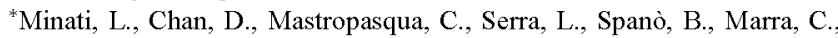
Bozzali, M. (2013). Widespread alterations in functional brain network architecture in amnestic mild cognitive impairment. Journal of Alzheimer's Disease, 40, 213-220.

${ }^{*}$ Morbelli, S., Drzezga, A., Perneczky, R., Frisoni, G. B., Caroli, A., van Berckel, B. N., . . Nobili, F. (2012). Resting metabolic connectivity in prodromal Alzheimer's disease. A European Alzheimer Disease Consortium (EADC) project. Neurobiology of Aging, 33, 2533-2550. doi: 10.1016/j.neurobiolaging.2012.01.005

Nakamura, T., Hillary, F. G., \& Biswal, B. B. (2009). Resting network plasticity following brain injury. PLoS ONE, 4, e8220. doi:10.1371/ journal.pone.0008220

"Neufang, S., Akhrif, A., Riedl, V., Förstl, H., Kurz, A., Zimmer, C., . . . Wohlschläger, A. M. (2011). Disconnection of frontal and parietal areas contributes to impaired attention in very early Alzheimer's disease. Journal of Alzheimer's Disease, 25, 309-321.

${ }^{*}$ Neufang, S., Akhrif, A., Riedl, V., Förstl, H., Kurz, A., Zimmer, C., . . Wohlschläger, A. M. (2013). Predicting effective connectivity from resting-state networks in healthy elderly and patients with prodromal Alzheimer's disease. Human Brain Mapping, 35, 954-963.

${ }^{*}$ Pagani, M., Salmaso, D., Rodriguez, G., Nardo, D., \& Nobili, F. (2009). Principal component analysis in mild and moderate Alzheimer's disease-a novel approach to clinical diagnosis. Psychiatry Research, 173, 8-14. doi:10.1016/j.pscychresns.2008.07.016

Palacios, E. M., Sala-Llonch, R., Junque, C., Roig, T., Tormos, J. M., Bargallo, N., \& Vendrell, P. (2012). White matter integrity related to functional working memory networks in traumatic brain injury. Neurology, 78, 852-860. doi: 10.1212/WNL.0b013e31824c465a 
Pandit, A. S., Expert, P., Lambiotte, R., Bonnelle, V., Leech, R., Turkheimer, F. E., Sharp, D. J. (2013). Traumatic brain injury impairs small-world topology. Neurology, 80, 1826-1833.

${ }^{*}$ Parisi, L., Rocca, M. A., Valsasina, P., Panicari, L., Mattioli, F., \& Filippi, M. (2012). Cognitive rehabilitation correlates with the functional connectivity of the anterior cingulate cortex in patients with multiple sclerosis. Brain Imaging Behavior. Advance online publication.

${ }^{*}$ Petrella, J. R., Sheldon, F. C., Prince, S. E., Calhoun, V. D., \& Doraiswamy, P. M. (2011). Default mode network connectivity in stable vs progressive mild cognitive impairment. Neurology, 76, 511-517. doi: 10.1212/WNL.0b013e31820af94e

${ }^{*}$ Prakash, R. S., Patterson, B., Janssen, A., Abduljalil, A., \& Boster, A. (2011). Physical activity associated with increased resting-state functional connectivity in multiple sclerosis. Journal of the International Neuropsychological Society, 17, 986-997. doi:10.1017/S135561 7711001093

*Qi, Z., Wu, X., Wang, Z., Zhang, N., Dong, H., Yao, L., \& Li, K. (2010). Impairment and compensation coexist in amnestic MCI default mode network. NeuroImage, 50, 48-55. doi:10.1016/j.neuroimage.2009.12 .025

Raichle, M. E., MacLeod, A. M., Snyder, A. Z., Powers, W. J., Gusnard, D. A., \& Shulman, G. L. (2001). A default mode of brain function. Proceedings of the National Academy of Sciences of the United States of America, 98, 676-682. doi:10.1073/pnas.98.2.676

Raichle, M. E., \& Snyder, A. Z. (2007). A default mode of brain function: A brief history of an evolving idea. Neuroimage, 37, 1083-1090. doi: 10.1016/j.neuroimage.2007.02.041

Ranganath, C., Cohen, M. X., \& Brozinsky, C. J. (2005a). Working memory maintenance contributes to long-term memory formation: Neural and behavioral evidence. Journal of Cognitive Neuroscience, 17 , 994-1010. doi:10.1162/0898929054475118

*Ranganath, C., \& D'Esposito M. (2005b). Directing the mind's eye: Prefrontal, inferior and medial temporal mechanisms for visual working memory. Current Opinion in Neurobiology, 15, 175-182. doi:10.1016/ j.conb.2005.03.017

${ }^{*}$ Richiardi, J., Gschwind, M., Simioni, S., Annoni, J. M., Greco, B., Hagmann, P., ... Van De Ville, D. (2012). Classifying minimally disabled multiple sclerosis patients from resting state functional connectivity. NeuroImage, 62, 2021-2033. doi:10.1016/j.neuroimage.2012.05 .078

${ }^{*}$ Ries, M. L., MeLaren, D. G., Bendlin, B. B., Guofan, xu, Rowley, H. A., Birn, R., . . Johnson, S. C. (2012). Medial prefrontal functional connectivity-relation to memory self-appraisal accuracy in older adults with and without memory disorders. Neuropsychologia, 50, 603-611. doi:10.1016/j.neuropsychologia.2011.12.014

${ }^{*}$ Rocca, M. A., Absinta, M., Moiola, L., Ghezzi, A., Colombo, B., Martinelli, V., . . Filippi, M. (2010). Functional and structural connectivity of the motor network in pediatric and adult-onset relapsing-remitting multiple sclerosis. Radiology, 254, 541-550. doi:10.1148/radiol .09090463

${ }^{*}$ Rocca, M. A., Absinta, M., Valsasina, P., Ciccarelli, O., Marino, S., Rovira, A., . . F Filippi, M. (2009b). Abnormal connectivity of the sensorimotor network in patients with MS: A multicenter fMRI study. Human Brain Mapping, 30, 2412-2425. doi:10.1002/hbm.20679

${ }^{*}$ Rocca, M. A., Bonnet, M. C., Meani, A., Valsasina, P., Colombo, B., Comi, G., \& Filippi, M. (2012a). Differential cerebellar functional interactions during an interference task across multiple sclerosis phenotypes. Radiology, 265, 864-873. doi:10.1148/radiol.12120216

${ }^{*}$ Rocca, M. A., Pagani, E., Absinta, M., Valsasina, P., Falini, A., Scotti, G., Comi, G. \& Filippi, M. (2007). Altered functional and structural connectivities in patients with MS: A 3-T study. Neurology 69, 2136-2145. doi:10.1212/01.wnl.0000295504.92020.ca

${ }^{*}$ Rocca, M. A., Valsasina, P., Ceccarelli, A., Absinta, M., Ghezzi, A., Riccitelli, G., . . Filippi, M. (2009a). Structural and functional MRI correlates of Stroop control in benign MS. Human Brain Mapping, 30 276-290. doi: $10.1002 / \mathrm{hbm} .20504$

${ }^{\text {*} R o c c a, ~ M . ~ A ., ~ V a l s a s i n a, ~ P ., ~ M a r t i n e l l i, ~ V ., ~ M i s c i, ~ P ., ~ F a l i n i, ~ A ., ~ C o m i, ~ G ., ~}$ \& Filippi, M. (2012b). Large-scale neuronal network dysfunction in relapsing-remitting multiple sclerosis. Neurology, 79, 1449-1457. doi: 10.1212/WNL.0b013e31826d5f10

${ }^{*}$ Rombouts, S. A., Damoiseaux, J. S., Goekoop, R., Barkhof, F., Scheltens, P., Smith, S. M., \& Beckmann, C. F. (2009). Model-free group analysis shows altered BOLD FMRI networks in dementia. Human Brain Mapping, 30, 256-266. doi: $10.1002 / \mathrm{hbm} .20505$

${ }^{*}$ Roosendaal, S. D., Hulst, H. E., Vrenken, H., Feenstra, H. E., Castelijns, J. A., Pouwels, P. J., . . Geurts, J. J. (2010). Structural and functional hippocampal changes in multiple sclerosis patients with intact memory function. Radiology, 255, 595-604. doi:10.1148/radiol.10091433

${ }^{*}$ Rosenbaum, R. S., Furey, M. L., Horwitz, B., \& Grady, C. L. (2010), Altered connectivity among emotion-related brain regions during shortterm memory in Alzheimer's disease. Neurobiology of Aging, 31, 780786. doi:10.1016/j.neurobiolaging.2008.06.002

Rypma, B., Berger, J. S., Prabhakaran, V., Bly, B. M., Kimberg, D. Y., Biswal, B. B., \& D'Esposito, M. (2006). Neural correlates of cognitive efficiency. NeuroImage, 33, 969-979. doi:10.1016/j.neuroimage.2006 .05 .065

${ }^{*}$ Rytsar, R., Fornari, E., Frackowiak, R. S., Ghika, J. A., \& Knyazeva, M. G. (2011). Inhibition in early Alzheimer's disease: An fMRI-based study of effective connectivity. Neurolmage, 57, 1131-1139. doi: 10.1016/j.neuroimage.2011.05.029

${ }^{*}$ Saini, S., DeStefano, N., Smith, S., Guidi, L., Amato, M. P., Federico, A., \& Matthews, P. M. (2004). Altered cerebellar functional connectivity mediates potential adaptive plasticity in patients with multiple sclerosis. Journal of Neurology, Neurosurgery \& Psychiatry, 75, 840-846. doi: 10.1136/jnnp. 2003.016782

Salthouse, T. A., Babcock, R. L., \& Shaw, R. J. (1991). Effects of adult age on structural and operational capacities in working memory. Psychology and Aging, 6, 118-127. doi:10.1037/0882-7974.6.1.118

Salthouse, T. A., \& Coon, V. E. (1993). Influence of task-specific processing speed on age differences in memory. Journal of Gerontology, 48 P245-P255. doi:10.1093/geronj/48.5.P245

Sanz-Arigita, E. J., Schoonheim, M. M., Damoiseaux, J. S., Rombouts, S. A., Maris, E., Barkhof, F., . . Stam, C. J. (2010). Loss of 'smallworld' networks in Alzheimer's disease: Graph analysis of FMRI resting-state functional connectivity. PLoS ONE, 5, e13788. doi: 10.1371/journal.pone.0013788

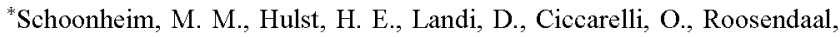
S. D., Sanz-Arigita, E. J., . . . Geurts, J. J. (2012). Gender-related differences in functional connectivity in multiple sclerosis. Multiple Sclerosis, 18, 164-173. doi:10.1177/1352458511422245

${ }^{*}$ Schwindt, G. C., Chaudhary, S., Crane, D., Ganda, A., Masellis, M., Grady, C. L., . . Black, S. E. (2013). Modulation of the default-mode network between rest and task in Alzheimer's disease. Cerebral Cortex, 23, 1685-1694.

${ }^{*}$ Seo, E. H., Lee, D. Y., Lee, J. M., Park, J. S., Sohn, B. K., Lee, D. S., ...Woo, J. I. (2013). Whole-brain functional networks in cognitively normal, mild cognitive impairment, and Alzheimer's disease. PLOS ONE, 8, e53922. doi:10.1371/journal.pone.0053922

Seymour, S. E., Reuter-Lorenz, P. A., \& Gazzaniga, M. S. (1994). The disconnection syndrome. Basic findings reaffirmed. Brain, 117, 105115. doi: 10.1093/brain/117.1.105

Sharp, D. J., Beckmann, C. F., Greenwood, R., Kinnunen, K. M., Bonnelle, V., De Boissezon, X., . . . Leech, R. (2011). Default mode network functional and structural connectivity after traumatic brain injury. Brain, 134, 2233-2247. doi:10.1093/brain/awr175

Sheline, Y. I., \& Raichle, M. E. (2013). Resting state functional connectivity in preclinical Alzheimer's disease. Biological Psychiatry, 74, $340-347$. 
Solé-Padullés, C., Bartrés-Faz, D., Lladó, A., Bosch, B., Peña-Gómez, C., Castellví, M., . . Molinuevo, J. L. (2013). Donepezil treatment stabilizes functional connectivity during resting state and brain activity during memory encoding in Alzheimer's disease. Journal of Clinical Psychopharmacology, 33, 199-205. doi:10.1097/JCP.0b013e31 82825 bfd

"Song, J., Qin, W., Liu, Y., Duan, Y., Liu, J., He, X., . . Yu, C. (2013). Aberrant functional organization within and between resting-state networks in AD. PLoS ONE, 8, e63727.

${ }^{*}$ Sorg, C., Riedl, V., Mühlau, M., Calhoun, V. D., Eichele, T., Läer, L., . . . Wohlschläger, A. M. (2007). Selective changes of resting-state networks in individuals at risk for Alzheimer's disease. Proceedings of the $\mathrm{Na}$ tional Academy of Sciences of the United States of America, 104, 18760-18765. doi:10.1073/pnas.0708803104

Sporns, O. (2011a). Networks of the brain. Cambridge, MA: Massachusetts Institute of Technology Press.

Sporns, O. (2011b). The human connectome: A complex network. Annals of the New York Academy of Sciences, 1224, 109-125. doi:10.1111/j $.1749-6632.2010 .05888 . x$

Stam, C. J., de Haan, W., Daffertshofer, A., Jones, B. F., Manshanden, I., van Cappellen van Walsum, A. M., ... . Scheltens, P. (2009). Graph theoretical analysis of magnetoencephalographic functional connectivity in Alzheimer's disease. Brain, 132, 213-224. doi:10.1093/brain/awn262

Stam, C. J., Jones, B. F., Manshanden, I., van Cappellen van Walsum, A. M., Montez, T., Verbunt, J. P., . . Scheltens, P. (2006). Magnetoencephalographic evaluation of resting-state functional connectivity in Alzheimer's disease. Neurolmage, 32, 1335-1344. doi:10.1016/j .neuroimage.2006.05.033

Stam, C. J., Jones, B. F., Nolte, G., Breakspear, M., \& Scheltens, P. (2007). Small-world networks and functional connectivity in Alzheimer's disease. Cerebral Cortex, 17, 92-99. doi:10.1093/cercor/bhj127

Steffener, J., \& Stern, Y. (2012). Exploring the neural basis of cognitive reserve in aging. Biochimica Et Biophysica Acta, 1822, 467-473. doi: 10.1016/j.bbadis.2011.09.012

${ }^{*}$ Stevens, M. C., Lovejoy, D., Kim, J., Oakes, H., Kureshi, I., \& Witt, S. T. (2012). Multiple resting state network functional connectivity abnormalities in mild traumatic brain injury. Brain Imaging and Behavior, 6 , 293-318. doi:10.1007/s11682-012-9157-4

"Supekar, K., Menon, V., Rubin, D., Musen, M., \& Greicius, M. D. (2008). Network analysis of intrinsic functional brain connectivity in Alzheimer's disease. PLoS Computational Biology, 4, e1000100. doi:10.1371/ journal.pebi. 1000100

${ }^{*}$ Tecehio, F., Zito, G., Zappasodi, F., Dell' Acqua, M. L., Landi, D., Nardo, D., . . Filippi, M. M. (2008). Intra-cortical connectivity in multiple sclerosis: A neurophysiological approach. Brain, 131, 1783-1792. doi: 10.1093/brain/awn087

Tijms, B. M., Wink, A. M., de Haan, W., van der Flier, W. M., Stam, C. J., Scheltens, P., \& Barkhof, F. (2013). Alzheimer's disease: Connecting findings from graph theoretical studies of brain networks. Neurobiology of Aging, 34, 2023-2036.

${ }^{*}$ Tsirka, V., Simos, P. G., Vakis, A., Kanatsouli, K., Vourkas, M., Erimaki, S., Pachou, E., ... Micheloyannis, S. (2011). Mild traumatic brain injury: Graph-model characterization of brain networks for episodic memory. International Journal of Psychophysiology, 79, 89-96. doi: 10.1016/.j.ijpsycho.2010.09.006

${ }^{*}$ Turner, G. R., McIntosh, A. R., \& Levine, B. (2011). (2012). Prefrontal compensatory engagement in TBI is due to altered functional engagement of existing networks and not functional reorganization. Frontiers in Systems Neuroscience, 5, 9.

Tzourio-Mazoyer, N., Landeau, B., Papathanassiou, D., Crivello, F., Etard, O., Delcroix, N., Mazoyer, B. and Joliot, M. (2002). Automated anatomical labeling of activations in SPM using a macroscopic anatomical parcellation of the MNI MRI single-subject brain. Neuroimage 15 , 273-289.
${ }^{*}$ Valsasina, P., Rocea, M. A., Absinta, M., Sormani, M. P., Mancini, L., De Stefano, N., . . . Filippi, M. (2011). A multicentre study of motor functional connectivity changes in patients with multiple sclerosis. European Journal of Neuroscience, 33, 1256-1263. doi:10.1111/j.14609568.2011.07623.x

van den Heuvel, M. P., Stam, C. J., Kahn, R. S., \& Hulshoff Pol, H. E. (2009). Efficiency of functional brain networks and intellectual performance. The Journal of Neuroscience, 2009, 29, 7619-7624. doi 10.1523/JNEUROSCI.1443-09.2009

van den Heuvel, M. P., Kahn, R. S., Goñi, J., \& Sporns, O. (2012) High-cost, high-capacity backbone for global brain communication. Proceedings of the National Academy of Sciences of the United States of America, 109, 11372-11377. doi:10.1073/pnas. 1203593109

${ }^{*}$ Verdoorn, T. A., McCarten, J. R., Arciniegas, D. B., Golden, R., Moldauer, L., Georgopoulos, A., . . Rojas, D. C. (2011). Evaluation and tracking of Alzheimer's disease severity using resting-state magnetoencephalography. Journal of Alzheimer's Disease, 26, 239-255

Vlassenko, A. G., Vaishnavi, S. N., Couture, L., Sacco, D., Shannon, B. J., Mach, R. H., et al. (2010). Spatial correlation between brain aerobic glycolysis and amyloid-beta (Abeta) deposition. Proceedings of the National Academy of Sciences of the United States of America, 107, 17763-17767. doi:10.1073/pnas.1010461107

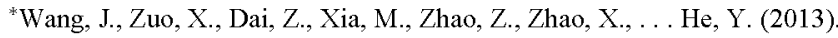
Disrupted functional brain connectome in individuals at risk for Alzheimer's disease. Biological Psychiatry, 73, 472-481. doi:10.1016/j .biopsych.2012.03.026

${ }^{*}$ Wang, K., Liang, M., Wang, L., Tian, L., Zhang, X., Li, K., \& Jiang, T. (2007). Altered functional connectivity in early Alzheimer's disease: A resting-state fMRI study. Human Brain Mapping, 28, 967-978. doi: $10.1002 / \mathrm{hbm} .20324$

${ }^{*}$ Wang, L., Li, H., Liang, Y., Zhang, J., Li, X., Shu, N., . . Z Zhang, Z. (2013). Amnestic mild cognitive impairment: Topological reorganization of the default-mode network. Radiology, 268, 501-514. doi: 10.1148 /radiol.13121573

${ }^{*}$ Wang, L., Li, H., Liang, Y., Zhang, J., Li, X., Shu, N., . . Zhang, Z. J. (2013). Amnestic mild cognitive impairment: Topological reorganization of the default-mode network. Radiology, 268, 501-514.

${ }^{*}$ Wang, L., Zang, Y., He, Y., Liang, M., Zhang, X., Tian, L., . . Li, K. (2006). Changes in hippocampal connectivity in the early stages of Alzheimer's disease: Evidence from resting state fMRI. NeuroImage, 31, 496-504. doi:10.1016/j.neuroimage.2005.12.033

${ }^{*}$ Wang, Y., Risacher, S. L., West, J. D., McDonald, B. C., Magee, T. R., Farlow, M. R., . . Saykin, A. J. (2013). Altered default mode network connectivity in older adults with cognitive complaints and amnestic mild cognitive impairment. Journal of Alzheimer's Disease, 35, 751-760.

${ }^{\text {*W}}$ Wang, Z., Jia, X., Liang, P., Qi, Z., Yang, Y., Zhou, W., \& Li, K. (2012). Changes in thalamus connectivity in mild cognitive impairment: Evidence from resting state fMRI. European Journal of Radiology, 81 , 277-285. doi:10.1016/j.ejrad.2010.12.044

${ }^{*}$ Wang, Z., Liang, P., Jia, X., Jin, G., Song, H., Han, Y., . . Li, K. (2012) The baseline and longitudinal changes of PCC connectivity in mild cognitive impairment: A combined structure and resting-state fMRI study. PLoS ONE, 7, e36838. doi:10.1371/journal.pone.0036838

${ }^{*}$ Wang, Z., Liang, P., Jia, X., Qi, Z., Yu, L., Yang, Y., . . Li, K. (2011). Baseline and longitudinal patterns of hippocampal connectivity in mild cognitive impairment: Evidence from resting state fMRI. Journal of Neurological Science, 309, 79-85. doi:10.1016/j.jns.2011.07.017

Wee, C. Y., Yap, P. T., Denny, K., Browndyke, J. N., Potter, G. G., Welsh-Bohmer, K. A., . . Shen, D. (2012). Resting-state multi-spectrum functional connectivity networks for identification of MCI patients. PLOS ONE, 7, e37828. doi:10.1371/journal.pone.0037828

${ }^{*}$ Wen, X., Wu, X., Li, R., Fleisher, A. S., Reiman, E. M., Wen, X., \& Chen, K., Yao, L. (2013). Alzheimer's disease-related changes in regional 
spontaneous brain activity levels and inter-region interactions in the default mode network. Brain Research, 1509, 58-65.

Werfel, J., Xie, X., \& Seung, H. S. (2005). Learning curves for stochastic gradient descent in linear feedforward. Neural Computation, 17, 26992718. doi:10.1162/089976605774320539

${ }^{*}$ Wu, X., Li, R., Fleisher, A. S., Reiman, E. M., Guan, X., Zhang, Y., . . . Yao, L. (2011). Altered default mode network connectivity in Alzheimer's disease-a resting functional MRI and Bayesian network study. Human Brain Mapping, 32, 1868-1881. doi:10.1002/hbm.21153

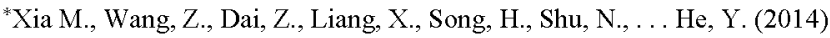
Differentially disrupted functional connectivity in posteromedial cortical subregions in Alzheimer's disease. Journal of Alzheimer's Disease, 39, $527-543$.

${ }^{*}$ Xie, C., Bai, F., Yu, H., Shi, Y., Yuan, Y., Chen, G., . . Li, S. J. (2012). Abnormal insula functional network is associated with episodic memory decline in amnestic mild cognitive impairment. Neurolmage, 63, 320327. doi:10.1016/j.neuroimage.2012.06.062

${ }^{*}$ Xie, C., Li, W., Chen, G., Ward, B. D., Franczak, M. B., Jones, J. L., . . Goveas, J. S. (2013). Late-life depression, mild cognitive impairment and hippocampal functional network architecture. NeuroImage: Clinical, 3, 311-320. doi:10.1016/j.nicl.2013.09.002

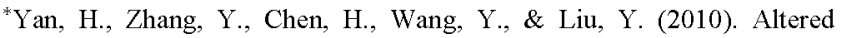
effective connectivity of the default mode network in resting-state amnestic type mild cognitive impairment. Journal of the International Neuropsychological Society, 21, 1-10.

${ }^{*}$ Yao, H., Liu, Y., Zhou, B., Zhang, Z., An, N., Wang, P., . . J Jiang, T. (2013). Decreased functional connectivity of the amygdala in Alzheimer's disease revealed by resting-state fMRI. European Journal of Radiology, 82, 1531-1538. doi:10.1016/j.ejrad.2013.03.019

Yao, Z., Zhang, Y., Lin, L., Zhou, Y., Xu, C., \& Jiang, T. (2010). Abnormal cortical networks in mild cognitive impairment and Alzheimer's disease. PLoS Computational Biology, 6, e1001006. doi:10.1371/ journal.pcbi. 1001006

${ }^{*} Y$ i, L., Wang, J., Jia, L., Zhao, Z., Lu, J., Li, K., . . Han, Y. (2012). Structural and functional changes in subcortical vascular mild cognitive impairment: A combined voxel-based morphometry and resting-state fMRI study. PLoS ONE, 7, e44758. doi:10.1371/journal.pone.0044758

Zalesky, A., Fornito, A., Egan, G. F., Pantelis, C., \& Bullmore, E. T. (2012). The relationship between regional and inter-regional functional connectivity deficits in schizophrenia. Human Brain Mapping, 33, 2535-2549. doi: $10.1002 / \mathrm{hbm} .21379$

"Zamboni, G., Wilcock, G. K., Douaud, G., Drazich, E., McCulloch, E., Filippini, N., . . Mackay, C. E. (2013). Resting functional connectivity reveals residual functional activity in Alzheimer's disease. Biological Psychiatry, 74, 375-383. doi:10.1016/j.biopsych.2013.04.015

*Zhang, H. Y., Wang, S. J., Liu, B., Ma, Z. L., Yang, M., Zhang, Z. J., \& Teng, G. J. (2010). Resting brain connectivity: Changes during the progress of Alzheimer disease. Radiology, 256, 598-606. doi:10.1148/ radiol.10091701

${ }^{*}$ Zhang, H. Y., Wang, S. J., Xing, J., Liu, B., Ma, Z. L., Yang, M., . . Teng, G. J. (2009). Detection of PCC functional connectivity characteristics in resting-state fMRI in mild Alzheimer's disease. Behavioural Brain Research, 30, 103-108.

${ }^{\text {*}}$ Zhang, J., Mitsis, E. M., Chu, K., Newmark, R. E., Hazlett, E. A., \& Buchsbaum, M. S. (2010). Statistical parametric mapping and cluster counting analysis of [18F] FDG-PET imaging in traumatic brain injury. Journal of Neurotrauma, 27, 35-49. doi:10.1089/neu.2009.1049

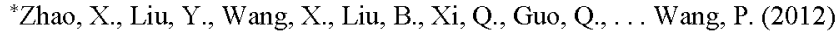
Disrupted small-world brain networks in moderate Alzheimer's disease: A resting-state FMRI study. PLoS ONE, 7, e33540. doi:10.1371/journal pone. 0033540

${ }^{*}$ Zhou, B., Liu, Y., Zhang, Z., An, N., Yao, H., Wang, P., . . J Jiang, T. (2013). Impaired functional connectivity of the thalamus in Alzheimer' $\mathrm{s}$ disease and mild cognitive impairment: A resting-state FMRI study. Current Alzheimer Research, 10, 754-766.

${ }^{*}$ Zhou, J., Greicius, M. D., Gennatas, E. D., Growdon, M. E., Jang, J. Y., Rabinovici, G. D., . . S Seeley, W. W. (2010). Divergent network connectivity changes in behavioural variant frontotemporal dementia and Alzheimer's disease. Brain, 133, 1352-1367. doi:10.1093/brain awq075

${ }^{*}$ Zhou, Y., Dougherty, J. H., Jr., Hubner, K. F., Bai, B., Cannon, R. L., \& Hutson, R. K. (2008). Abnormal connectivity in the posterior cingulate and hippocampus in early Alzheimer's disease and mild cognitive impairment. Alzheimer's \& Dementia, 4, 265-270. doi:10.1016/j.jalz.2008 .04 .006

${ }^{*}$ Zhu, D., Li, K., Terry, D. P., Puente, A. N., Wang, L., Shen, D., ... Liu, T. (2013). Connectome-scale assessments of structural and functional connectivity in MCI. Human Brain Mapping. Advance online publication.

${ }^{*}$ Zhu, D. C., Majumdar, S., Korolev, I. O., Berger, K. L., \& Bozoki, A. C. (2013). Alzheimer's disease and amnestic mild cognitive impairment weaken connections within the default-mode network: A multi-modal imaging study. Journal of Alzheimer's Disease, 34, 969-984.

Received October 5, 2013

Revision received April 28, 2014

Accepted April 29, 2014 